Article

\title{
Dynamic Structure and Stability of DNA Duplexes Bearing a Dinuclear Hg(II)-Mediated Base Pair
}

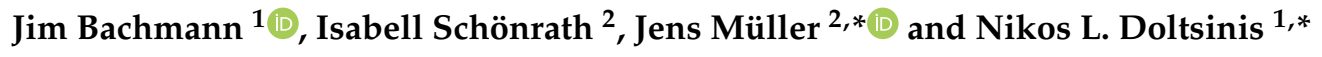 \\ 1 Institute for Solid State Theory and Center for Multiscale Theory and Computation, Westfälische-Wilhelms \\ Universität Münster, Wilhelm-Klemm-Straße 10, 48149 Münster, Germany; j_bach04@uni-muenster.de \\ 2 Institut für Anorganische und Analytische Chemie, Westfälische-Wilhelms Universität Münster, \\ Corrensstraße 30, 48149 Münster, Germany; isabell.schoenrath@uni-muenster.de \\ * Correspondence: mueller.j@uni-muenster.de (J.M.); nikos.doltsinis@wwu.de (N.L.D.); \\ Tel.: +49-251-833-6006 (J.M.); +49-251-833-3582 (N.L.D.)
}

Academic Editor: Martin Brehm

Received: 28 September 2020; Accepted: 22 October 2020; Published: 26 October 2020

check for updates

\begin{abstract}
Quantum mechanical (QM) and hybrid quantum mechanical/molecular mechanical (QM/MM) molecular dynamics simulations of a recently reported dinuclear mercury(II)-mediated base pair were performed aiming to analyse its intramolecular bonding pattern, its stability, and to obtain clues on the mechanism of the incorporation of mercury(II) into the DNA. The dynamic distance constraint was employed to find initial structures, control the dissociation process in an unbiased fashion and to determine the free energy required. A strong influence of the exocyclic carbonyl or amino groups of neighbouring base pairs on both the bonding pattern and the mechanism of incorporation was observed. During the dissociation simulation, an amino group of an adenine moiety of the adjacent base pair acts as a turnstile to rotate the mercury(II) ion out of the DNA core region. The calculations provide an important insight into the mechanism of formation of this dinuclear metal-mediated base pair and indicate that the exact location of a transition metal ion in a metal-mediated base pair may be more ambiguous than derived from simple model building.
\end{abstract}

Keywords: Ab initio calculations; DNA structures; molecular dynamics; free energy; mercury; $\mathrm{Hg}$ (II); metal-mediated base pairs; metal-modified DNA

\section{Introduction}

Nucleic acids with metal-mediated base pairs have been of interest in the development of functional nanostructures [1] as they feature robustness, programmable hybridization properties and a well-established automated synthesis [2,3]. Metal-mediated base pairs provide a convenient means for the site-specific functionalization of nucleic acids with metal ions. They can be formed from canonical nucleobases, with thymine and cytosine being the most prominent natural nucleobases capable of engaging in stable metal-mediated base pairs [4-6]. In this regard, thymine is known for its high affinity for mercury(II), whereas cytosine prefers binding to silver(I) [7-9]. In addition, many synthetic nucleobase analogues have been devised, broadening the metal-ion scope of metal-mediated base pairing. As a result, metal-mediated base pairs are known involving $\mathrm{Cu}(\mathrm{II}),[10-13]$ $\mathrm{Cu}(\mathrm{I}),[14] \mathrm{Mn}(\mathrm{III})$ [15], Ni(II) [16], Zn(II) [17], and other metal ions [18,19]. Nevertheless the most prominent metal ions used with artificial nucleobases remain $\mathrm{Ag}(\mathrm{I})$ and $\mathrm{Hg}(\mathrm{II})$, too [20-27]. Nucleic acids comprising metal-mediated base pairs have been applied in various manners, e.g., in the context of modulating the charge transfer capability of the nucleic acids [28-32], in metal-responsive structural transformations [33-35], in the formation of DNA-templated silver nanoclusters [36], and in oligonucleotide recognition [37-39]. Various experimental structures have been reported, confirming 
that the concept of metal-mediated base pairing is compatible with various DNA duplex topologies [40]. Interestingly, metal-mediated base pairs can even be introduced into nucleic acids enzymatically [41-47].

Depending on the type of artificial nucleobase used, even di- and trinuclear metal-mediated base pairs have been reported [48-51]. Recently, the first dinuclear metal-mediated base pair containing two mercury(II) ions as divalent metal ions has been reported [52]. The artificial nucleobase $1, N^{6}$-ethenoadenine $(\varepsilon \mathrm{A})$ had been employed in those studies because it had been shown to provide a unique coordination mode, with the lone pairs of its two coordinating nitrogen atoms being oriented in an almost parallel fashion. As a result, $\varepsilon \mathrm{A}$ is particularly suited for binding two metal ions at close distance to each other. Hence, the use of $\varepsilon$ A allowed for the first time the arrangement of two $\mathrm{Hg}$ (II) ions (bearing four positive charges) in a single metal-mediated base pairs. The bonding pattern of the resulting $\varepsilon \mathrm{A}-\mathrm{Hg}(\mathrm{II})_{2}-\mathrm{T}$ base pair has been explored at the Density Functional Theory (DFT) level for isolated base pairs [52]. Later, a slightly different geometry has been proposed for this base pair [53]. As mercury features a multitude of possible bonding patterns within DNA [54], we decided to study the bonding within this mercury(II)-modified DNA by the means of QM and QM/MM simulations. As no empirical structures of the solvated DNA duplex were available, we employed the so-called dynamic distance constraint [55] to find an initial geometry of the DNA in the preferred hydrogen bonding pattern. After this initial phase, all constraints are released for a further optimization, which preserved the hydrogen bonding structure.

Free energy simulations are performed to study the stability and possible dissociation paths of the novel DNA, where the neighbouring base pairs influence both the bonding pattern and the inclusion path of mercury(II) into the DNA.

\section{Computational Details}

\subsection{Static DFT Calculations}

The GAUSSIAN09 software [56] was utilized using density functional theory (DFT) employing the PBE0 hybrid-functional [57-60] and the SDD basis set [61,62] together with Grimme D3 corrections with Becke-Johnson damping [63,64] and the PCM continuum solvation model [65].For convergence criteria the Gaussian Tight option was chosen.

The influence of relativistic effects and different exchange-correlation functionals was investigated using the ORCA 3.0.3 software [66]. The functionals PBE, PBE0, BP86, PM6, BLYP and B3LYP were chosen with basis sets TZVP and SDD. Scalar relativistic ZORA corrections [67] were evaluated using special scalar relativistic basis sets [68]. As convergence criteria the NormalSCF criteria of ORCA were set.

\subsection{Topology Generation for Classical Molecular Dynamics}

Using the program tleap from the AMBERTOOLS package [69], the PARMbsc1 force field [70] specially refined for DNA simulations and $\mathrm{Hg}$ van der Waals parameters devised by Fuchs et al. [71], a topology was generated for the DNA double helix. A parametrization of isoguanine was not available, so a force field was parametrized with RESP charges [72], bond lengths and angles from the DFT/PBE0/SDD optimization of the isolated base pair and bond strength parameters from the guanine parameters of PARMbsc1. The thus prepared DNA was then solvated by tleap in a $12 \AA$ thick water shell to screen self-interactions. This resulted in an orthorhombic box with side lengths $44.41 \AA, 44.57 \AA$ and $63.41 \AA$ including 3073 water molecules and $23 \mathrm{Na}^{+}$counter ions, neutralizing 26 negative charges due to the phosphate backbone and the three positive charges of the modified base pair, leading to an overall charge-neutral system.

For the isolated base pair, a new set of partial atomic charges was generated from a GAUSSIAN09 DFT calculation with the SDD basis and the PBE0 functional, Grimme-D3 corrections, PCM implicit solvation and the CHelpG method, which assigns RESP charges to each atom. 


\subsection{Classical Molecular Dynamics}

Classical molecular dynamics (MD) simulations were performed using the FIST method of CP2K [73] with the PARMbsc1 force field [70] for the DNA and the $\mathrm{Na}^{+}$counterions, with the modifications for isoguanine described above. Water molecules were described by the TIP3P water model [74,75]. A time step of $0.5 \mathrm{fs}$ was chosen. Equilibration runs were performed in the NPT ensemble using the Nose-Hoover barostat and thermostat with a chain length of 3 and a time constant of 1 ps. The target temperature was set to $300 \mathrm{~K}$ in all NVT and NPT runs and the target pressure to 1 bar in all NPT MDs.

\subsection{Ab Initio Molecular Dynamics and Optimization}

DFT based ab initio molecular dynamics simulations were carried out with the CP2K program using the GAPW scheme [76,77]. The PBE functional was chosen together with the TZVP-MOLOPT basis set for all atoms except mercury, for which a DZVP-MOLOPT basis was utilized [78], in conjunction with Goedecker-Teter-Hutter pseudopotentials [79-81] and a plane wave cut-off of 400 Ry. Grimme D3 dispersion corrections were employed with Becke-Johnson damping [63,64]. A total of 700 virtual molecular orbitals were calculated for Fermi-Dirac smearing due to the presence of the transition metal mercury. Cholesky inversion was chosen as the solver of the eigenvalue problem, while Broyden mixing was employed for optimization. MD was performed with a time step of $0.5 \mathrm{fs}$.

The convergence criteria for the geometry optimization were set to 0.003 a.u. for the maximum step size, 0.0015 a.u. for the root-mean-square (RMS) displacement of atomic positions, 0.0004 a.u. for gradients and 0.003 a.u. for the RMS change of the gradients.

\subsection{QM/MM Simulations}

QM/MM molecular dynamics simulations were carried out with the CP2K program, where for the classical region the settings from 2.3 were applied. For the QM region, settings from Section 2.4 were used. The QM region consisted of all atoms of the metal-modified base pair (Figure 1a) and the base pairs directly above and below. Furthermore, three negatively charged phosphate groups together with the attached backbone structure were incorporated into the QM subsystem to neutralize the threefold positive charge of the metal-modified base pair leading to an overall charge-neutral QM subsystem with multiplicity 1 , which proved crucial for obtaining reasonable geometries and stable MD simulations. Coupling was treated with the Gaussian expansion of electrostatic potentials (GEEP) method in $\mathrm{CP} 2 \mathrm{~K}$, where the IMOMM method was utilized to treat the links between MM and QM [82].
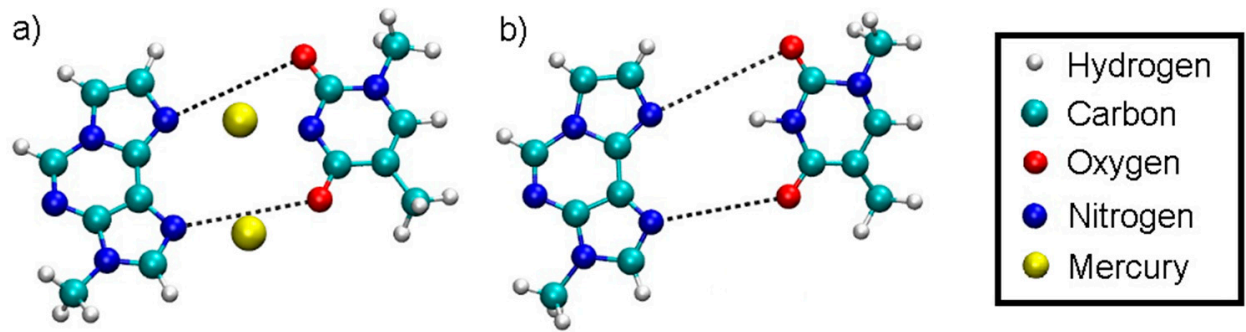

Figure 1. Definition of the dynamic distance within the plane of the modified base pair with $\mathrm{Hg}$ (a) and without $\mathrm{Hg}(\mathbf{b})$. The dynamic distance within the plane of the isolated base pair is defined in the same way as for the complete DNA duplex.

\subsection{Free Energy Calculations}

\subsubsection{Dynamic Distance Constraint}

Five different model systems termed structure 1-5, which will be presented in Section 3, were investigated by free energy calculations. 
As a reaction coordinate, we chose the dynamic distance [55].

$$
D=\left(\sum_{\mathrm{NOP}} \frac{\mu_{i j}}{\mu^{*}}\left(r_{i}-r_{j}\right)^{2}\right)^{\frac{1}{2}}
$$

where NOP are all non-overlapping pairs $i, j$ of atoms between which the constraint is defined, $r_{i}$ and $r_{j}$ are their positions, $\mu_{i j}=m_{i} m_{j} /\left(m_{i}+m_{j}\right)$ is their reduced mass and $\mu^{*}=\sum_{\mathrm{NOP}} \mu_{i j}$ is the sum of all reduced masses.

In the case of the full DNA models $D=D_{\text {DNA }}$ includes all $\mathrm{N} \cdots \mathrm{H}$ hydrogen bonds within regular base pairs and the two $\mathrm{N}$... O distances bridged by $\mathrm{Hg}(\mathrm{II})$ ions (Figure 1). In the case of the isolated base-pair models, the two $\mathrm{O} \cdots \mathrm{N}$ distances according to Figure 1 were selected to enter the dynamic distance $D=D_{\text {ISO }}$.

\subsubsection{Thermodynamic Integration}

The dynamic distance was incrementally increased and the average Lagrange multiplier at every constraint value, corresponding to the average constraint force $\langle F(D)\rangle$, calculated. Integrating over the mean constraint force along the dynamic distance gives the free energy necessary to dissociate the system:

$$
\Delta A=\int_{D_{\min }}^{D_{\max }}\langle F(D)\rangle d D
$$

Structures 1, 2, and 3 were simulated for $500 \mathrm{fs}$ at the initial dynamic distance before starting the dissociation $\mathrm{MD}$, to allow for further equilibration of the quantum region. The running average of the Lagrange multipliers are shown in Figure S4 for structure 1, Figure S5 for structure 2 and Figure S6 for structure 3. For the calculations involving structure 1, the dynamic distance was initially set to $3.0 \AA$ and increased/decreased by $0.2 \AA$ at each simulation point, where each point was simulated for at least 1 ps. Overall 41360 simulation steps were performed for structure 1, equalling 20.58 ps. At the final point of $D_{\text {DNA }}=5.8 \AA$ of the trajectory, the modified base pair was found to be dissociated and one $\mathrm{Hg}$ (II) ion was in contact with water. Hence, the simulation was not continued further as this would have led to unphysical water-mercury interactions across the QM/MM boundary. Structure 2 was less stable during the dissociation simulation, thus requiring smaller dynamic distance steps of $0.1 \AA$. The system was simulated from an initial value of $D_{\mathrm{DNA}}=3.7 \AA$ up to a final value of $D_{\mathrm{DNA}}=10.5 \AA$, at which point only a change in the bonding pattern occurred instead of dissociation. However, as one mercury ion was already in contact with $\mathrm{MM}$ water at this $D_{\mathrm{DNA}}$, the simulation was not continued further. Each $D$ point was simulated for at least 1 ps, amounting to an overall simulation length of 62 ps. Structure 3 was simulated with a dynamic distance step size of $0.1 \AA$ from $D_{\text {DNA }}=2.5 \AA$ to $D_{\mathrm{DNA}}=3.5 \AA$ and a step size of $0.5 \AA$ for the remaining points up to $D_{\mathrm{DNA}}=8.5 \AA$. The overall simulation length for structure 3 was about 35 ps, after which the modified base pair was sufficiently dissociated (see Figure S3).

In the all-QM simulations, structures 4 and 5 were dissociated by an increase of the dynamic distance between the $\mathrm{N}$ and $\mathrm{O}$ atoms of the modified base pair (Figure 8 ), termed $D_{\text {ISO, with settings }}$ given in Section 2.4. The system was simulated for $500 \mathrm{fs}$ at the initial value of the dynamic distance constraint, which was subsequently increased in steps of $0.2 \AA$. An all-QM MD was performed with the CP2k code, with identical settings as before but with all water molecules described by DFT. A total of ca. 6 ps were simulated for structure 4 and ca. 13 ps for structure 5 .

\section{Model Structures}

In total, five different model structures were simulated, three of which were complete DNA models and two were isolated base pairs in solution. Their generation will be described below. 


\subsection{Generation of the Initial DNA Geometry}

Five different initial structures are simulated by means of molecular dynamics and geometry optimizations to study the bonding patterns of the novel artificial T:cA base-pair (Figure 2). As no experimental structures of this mercury(II)-containing DNA duplex are available, the initial geometries were generated by using the 3DNA software [83] for the sequence 3'-d(GAAAGATAGGGAG)-5'/5'-d(CTCCCTATCTTTC)-3'. One DNA strand was then rotated by $180^{\circ}$ and placed back into a helical structure, to generate parallel-stranded DNA as used in the previous experiments (Figure 3). This was followed by an exchange of the exocyclic $\mathrm{O}$ and $\mathrm{NH}_{2}$ groups of all guanines, transforming them into isoguanines, thus generating the duplex

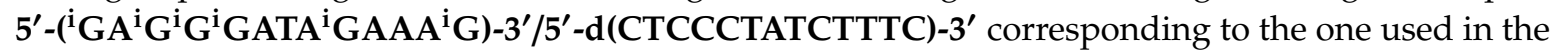
original experiments [52] except for the modification of the central A:T base pair.

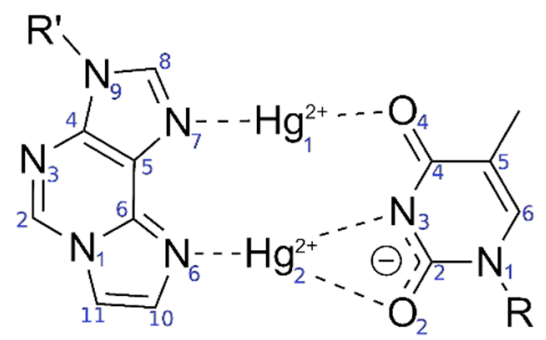

Figure 2. Originally proposed [52] bonding pattern of the dinuclear mercury(II)-mediated base pair between $1, N^{6}$-ethenoadenine $(\varepsilon \mathbf{A})$ and thymine $(\mathbf{T})$, including the atom numbering according to IUPAC recommendations in blue.

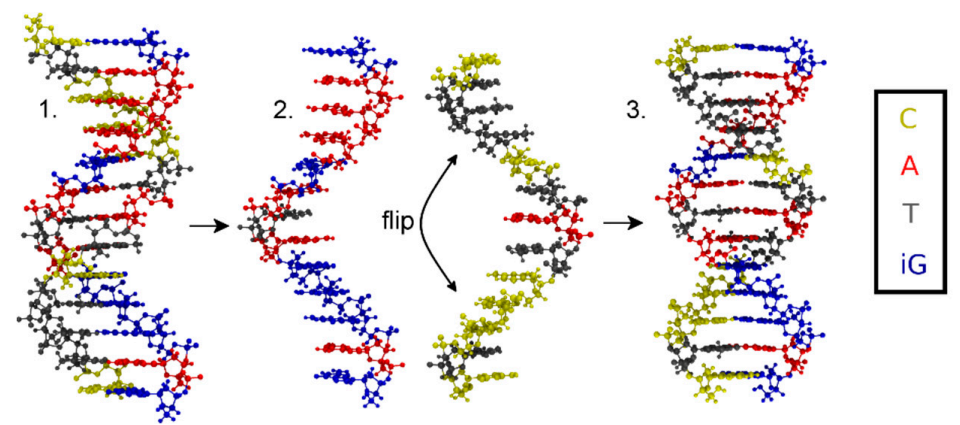

Figure 3. Flowchart depicting the generation of the initial structure with (iso)guanine residues depicted in blue, adenine in red, thymine in grey and cytosine in yellow. 1. Antiparallel-stranded DNA obtained from 3DNA; 2 . Separated strands, where one stand is flipped by $180^{\circ} ; 3$. Reattached strands forming parallel-stranded DNA.

Only standard bases are available in the 3DNA program; thus, a thymine:adenine (T:A) base pair was generated at the site of the modified base pair. The atomic vacuum structure of the modified thymine:1, $N^{6}$-ethenoadenine (T:عA) pair was optimized using the settings from Section 2.1. The electric charge of the base pair is +3 , its spin multiplicity 1 . The resulting structure is shown in Figure 4 . This structure closely resembles that reported in reference 53 for this base pair.

To assess the influence of the neighbouring base pairs onto the equilibrium geometry of the artificial base pair, further DFT geometry optimizations including the base pairs above and below $\mathbf{T}$ : $\varepsilon \mathbf{A}$ have been performed with identical functionals and basis set as the metal-mediated base pair alone. In this model, adjacent base pairs are connected via a phosphate backbone. Due to the four phosphate moieties connecting the three base pairs, the charge of the system is now -1 and the multiplicity 1 . Figure 5 displays the resulting structure. This structure is more similar to the originally proposed base pair geometry from reference 52 . 


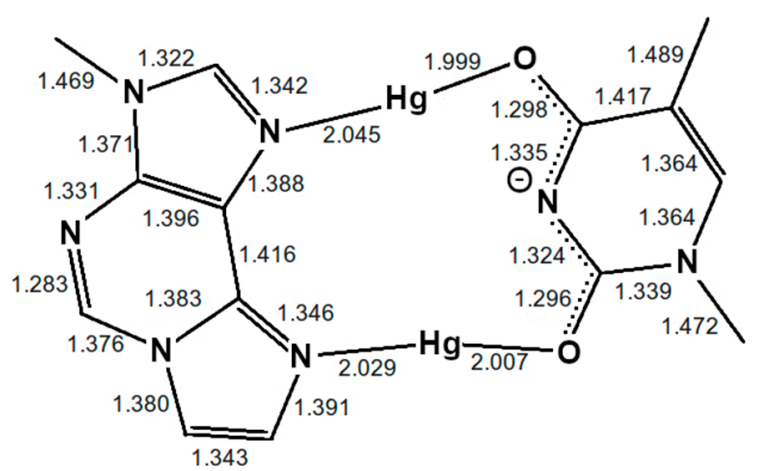

Figure 4. Optimized structure of the $\varepsilon \mathbf{A}-\mathrm{Hg}(\mathrm{II})_{2}-\mathbf{T}$ base pair with interatomic distances in $\AA$. The N3 atom of thymine is deprotonated. Both mercury(II) ions form coordinate bonds involving one nitrogen atom of $\varepsilon \mathbf{A}(\mathrm{N} 6$ or N7) and one oxygen atom of $\mathbf{T}(\mathrm{O} 2$ or $\mathrm{O} 4)$, resulting in the NO-bonding pattern.

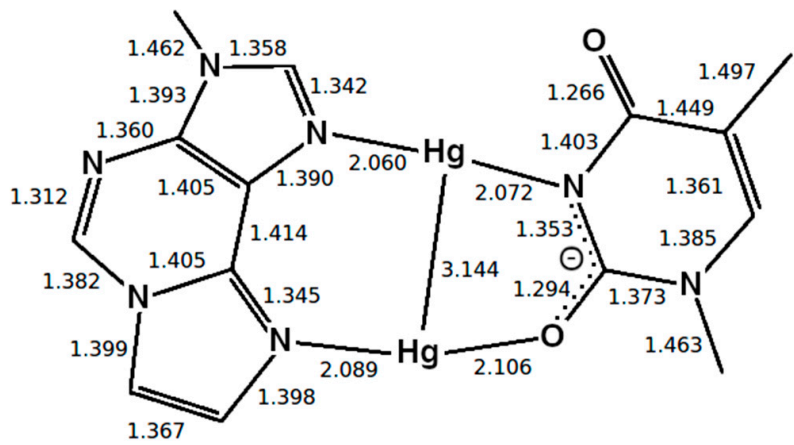

Figure 5. Optimized structure of the $\varepsilon \mathbf{A}-\mathrm{Hg}(\mathrm{II})_{2}-\mathbf{T}$ base pair with interatomic distances in $\AA$, where the presence of neighbouring base pairs was taken into consideration, too. Only the metal-mediated base pair is shown. The mercury(II) previously attached to T-O4 changes its bonding pattern, now being located between two nitrogen atoms (NN-bonding pattern).

Two different bonding patterns emerged during the geometry optimization. Within the isolated base pair, the mercury ion $\mathrm{Hg} 2$ is located in between the $\varepsilon \mathbf{A}-\mathrm{N} 6$ and T-O2 atoms, while $\mathrm{Hg} 1$ coordinates to the $\varepsilon \mathbf{A}-\mathrm{N} 7$ and T-O4 atoms (NO bonding pattern, Figure 4). When the adjacent pairs are also taken into account, $\mathrm{Hg} 2$ remains located between the $\varepsilon \mathbf{A}-\mathrm{N} 6$ and T-O2 atoms, while $\mathrm{Hg} 1$ changes its bonding pattern and is now coordinated to $\varepsilon \mathbf{A}-\mathrm{N} 7$ and T-N3 (NN bonding pattern, Figure 5). These two structures correspond to two minima on the potential energy surface and exist for both the isolated and the stacked base pair. In the isolated case, the NO bonding pattern represents the global minimum structure. This has been confirmed for a number of different exchange-correlation functionals given in Section 2.1; an overview of the results is tabulated in Figure S7. In the three base pair stack, the NN bonding pattern is favoured (Figure 5), where the neighbouring $\mathrm{N}$ and $\mathrm{O}$ atoms from the nucleobases above and below attract the mercury ions, if they are situated directly on top or below them.

As the PBE functional correctly predicts the NO pattern to be the more stable configuration for the isolated base pair, it was chosen as the exchange-correlation functional for the QM/MM and the all-QM MD runs in view of its computational advantage compared with hybrid functionals. Relativistic corrections did not change the observed bonding pattern (see Figure S7) and were thus not included in the MD runs. Because the TZVP basis led to a further stabilization of the NO compared to the NO pattern, the TZVP-MOLOPT basis was chosen for use during the MD.

Replacing the nucleobases of the T:A base pair in the centre of the DNA duplex by the modified base pair T:EA within the geometry from Figure 4 led to the desired initial structure $5^{\prime}-\left(^{\mathrm{i}} \mathrm{GA}^{\mathrm{i}} \mathrm{G}^{\mathrm{i}} \mathrm{G}^{\mathrm{i}} \mathrm{GATA}^{\mathrm{i}}{ }^{\mathrm{GAAA}}{ }^{\mathrm{i}} \mathrm{G}\right)-\mathbf{3}^{\prime} / 5-\mathrm{d}^{\prime}\left(\mathrm{CTCCCT}\right.$ ATCTTTC)-3' ${ }^{\prime}$, which is depicted in Figure 6 along with the nucleobase numbering scheme. 
a)

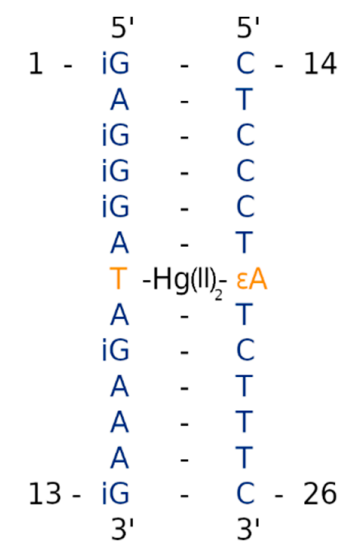

b)

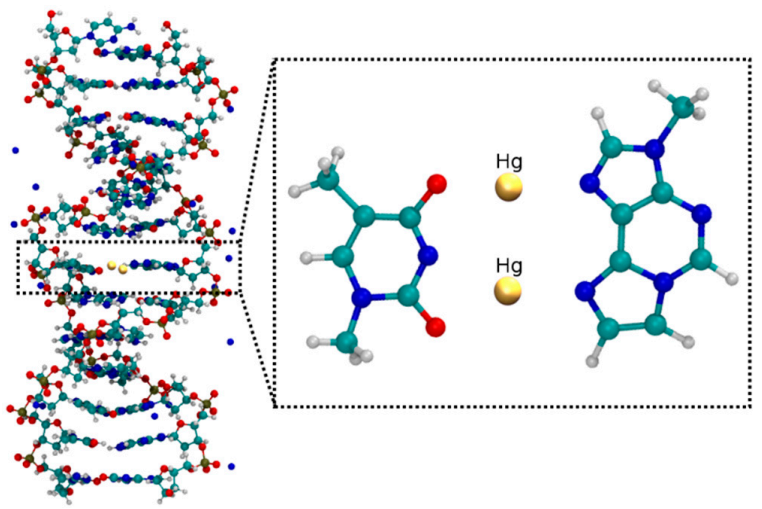

Figure 6. (a) Parallel-stranded DNA duplex with numbering of the nucleobases from the $5^{\prime}$ to the $3^{\prime}$ end. T7 is deprotonated and forms a dinuclear $\mathrm{Hg}(\mathrm{II})$-mediated base pair with the modified base $\varepsilon$ A20. (b) Insertion of the $\mathrm{T} 7-\mathrm{Hg}(\mathrm{II})_{2}-\varepsilon \mathbf{A} 20$ base pair into the parallel-stranded DNA duplex. Only the DNA and the $\mathrm{Na}^{+}$counter-ions are displayed, while water molecules are not shown.

The topology of the DNA for classical MD was generated as described in Section 2.2.

\subsection{Zipping up the DNA by a Dynamic Distance Constraint}

The initially prepared structure was still in a very high-energy, non-equilibrated state. To relax the geometry, classical MD runs and geometry optimizations were performed using the dynamic distance constraint (Section 2.6.1). This enables fixing the overall hydrogen-bond structure of the DNA during equilibration, while allowing individual hydrogen bond distances to change, which is needed to equilibrate the double helix without it breaking apart into two strands. Because no parametrization of the $\mathrm{N}-\mathrm{Hg}$ (II) and $\mathrm{O}-\mathrm{Hg}$ (II) bonds within the modified bases was available, all atoms of the modified base pair (except for the deoxyribose moieties and the phosphate backbone) were fixed at the equilibrium geometry from the optimization from Section 3.1, Figure 4 during purely classical $\mathrm{MD}$, with the computational details given in Section 2.3. With all hydrogen bonds between base pairs selected as a dynamic distance constraint $D_{\mathrm{EQUI}}$, this dynamic distance was gradually reduced from an initial value of $D_{\mathrm{EQUI}}=1.88 \AA$ to $D_{\mathrm{EQUI}}=1.56 \AA$ during an NPT MD simulation with the settings given in Section 2.3 over 10,000 steps, thus "zipping up" the DNA hydrogen bond structure (Figure 7).

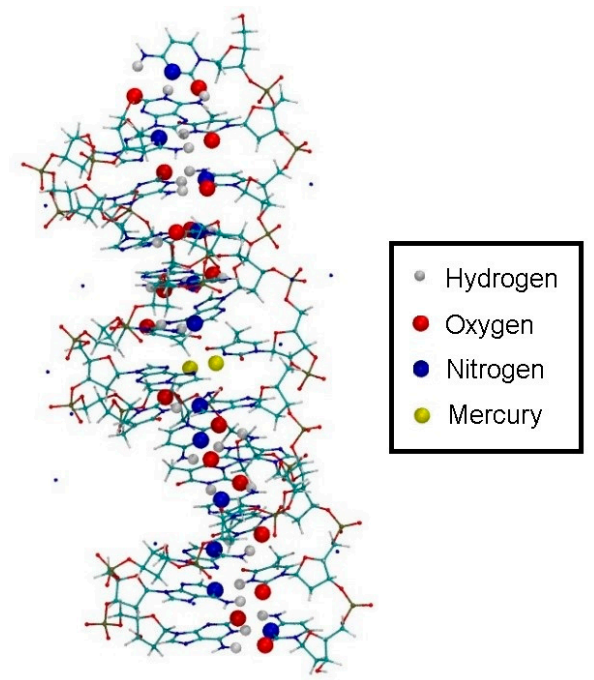

Figure 7. Zipping up the DNA by a dynamic distance constraint across all hydrogen bonds of the non-modified bases. The oxygen, nitrogen and hydrogen atoms shown as large spheres are the constrained partners, where the sum of all bonds represents the dynamic distance. 


\subsection{Relaxing the DNA Backbone by Geometry Optimization}

Simulated annealing starting from the NPT-equilibrated temperature of $300 \mathrm{~K}$ was applied during the subsequent 30,000 steps with an annealing factor of 0.99 to slowly relax the DNA duplex. This was followed by a QM/MM geometry optimization [84,85] using CP2K with all constraints released. The computational details are given in Section 2.5.

\subsection{Relaxing the DNA Structure at Finite Temperature}

\subsubsection{Structure 1}

Subsequent to the geometry optimization, a classical MD simulation was performed in the NPT ensemble for pressure equilibration for $1.7 \mathrm{~ns}$ and settings from Section 2.3, keeping all atoms of the modified base pair (except for the sugar and phosphate backbone) fixed due to the absence of suitable force field parameters, however releasing the dynamic distance constraint. As the hydrogen bond structure persisted during optimization and MD without the use of the dynamic distance constraint, we considered the DNA duplex to be in a chemical reasonable structure, which we chose as a basis for our further investigations. This resulted in a unit cell of size $43.29 \AA \times 44.53 \AA \times 63.33 \AA$, corresponding to a density of $985 \mathrm{~kg} / \mathrm{m}^{3}$. The resulting structure is referred to as structure $\mathbf{1}$ (Figure 8).

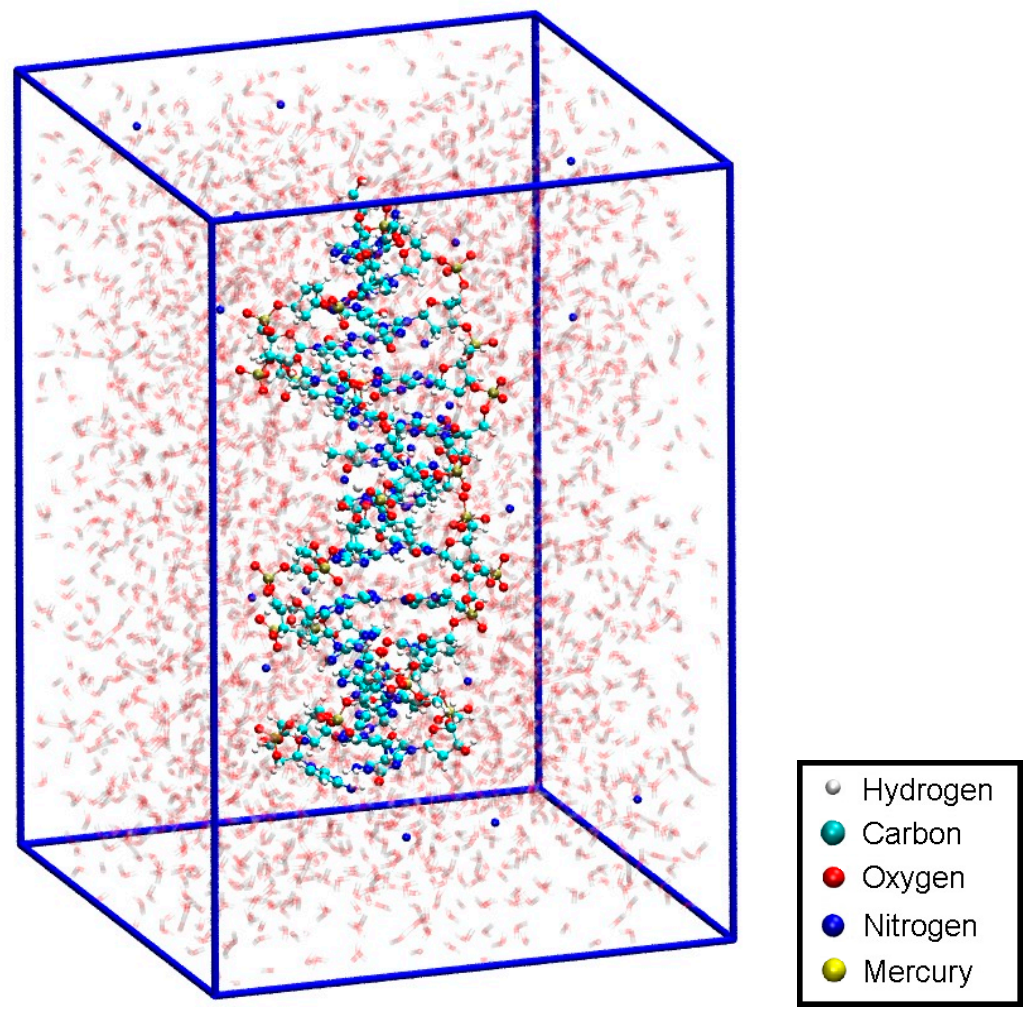

Figure 8. Initial structure 1 within the simulation box, with $\mathrm{Na}^{+}$ions displayed in blue and water molecules shown transparent.

\subsubsection{Structure 2}

The dynamic distance method was subsequently employed again as a reaction coordinate to simulate the dissociation of DNA and to determine the corresponding free energy profile. In this case, the dynamic distance $D_{\mathrm{DNA}}$ comprises all $\mathrm{N} \cdots \mathrm{H}$ hydrogen bonds of all regular base pairs together with the two N...O distances bridged by the two Hg ions in the metal-mediated base pair (Figure 1a). Thereby

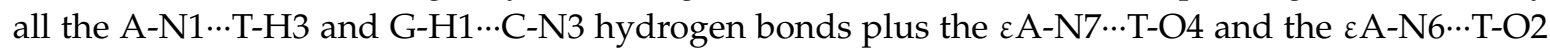


distances in the modified base pair are subject to the dynamic distance constraint. These are the nonoverlapping pairs (NOP) specified in the formula for $D$ given in Section 2.6.1.

This collective variable has the advantage of not biasing the dissociation process, i.e., not favouring a particular pathway. At the initial point of $D_{\text {DNA }}=3.7 \AA$, a QM/MM molecular dynamics simulation was performed for 4000 steps, resulting in a different structure with $\mathrm{Hg} 1$ positioned in-between $\varepsilon \mathrm{A} 20$, T7 and T8, and a proton being transferred from T19 to A6 (Figure 9b). Hg2 then cross-links the bases

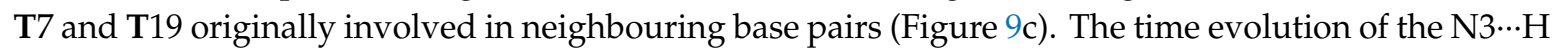
and $\mathrm{N} 3 \cdots \mathrm{Hg} 2$ distances during deprotonation of T19-N3 are depicted in Figure 10, showing that as the proton leaves, its binding position approaches the $\mathrm{Hg} 2$ ion. The resulting structure is used as the initial structure 2 for the second dissociation path of the DNA.
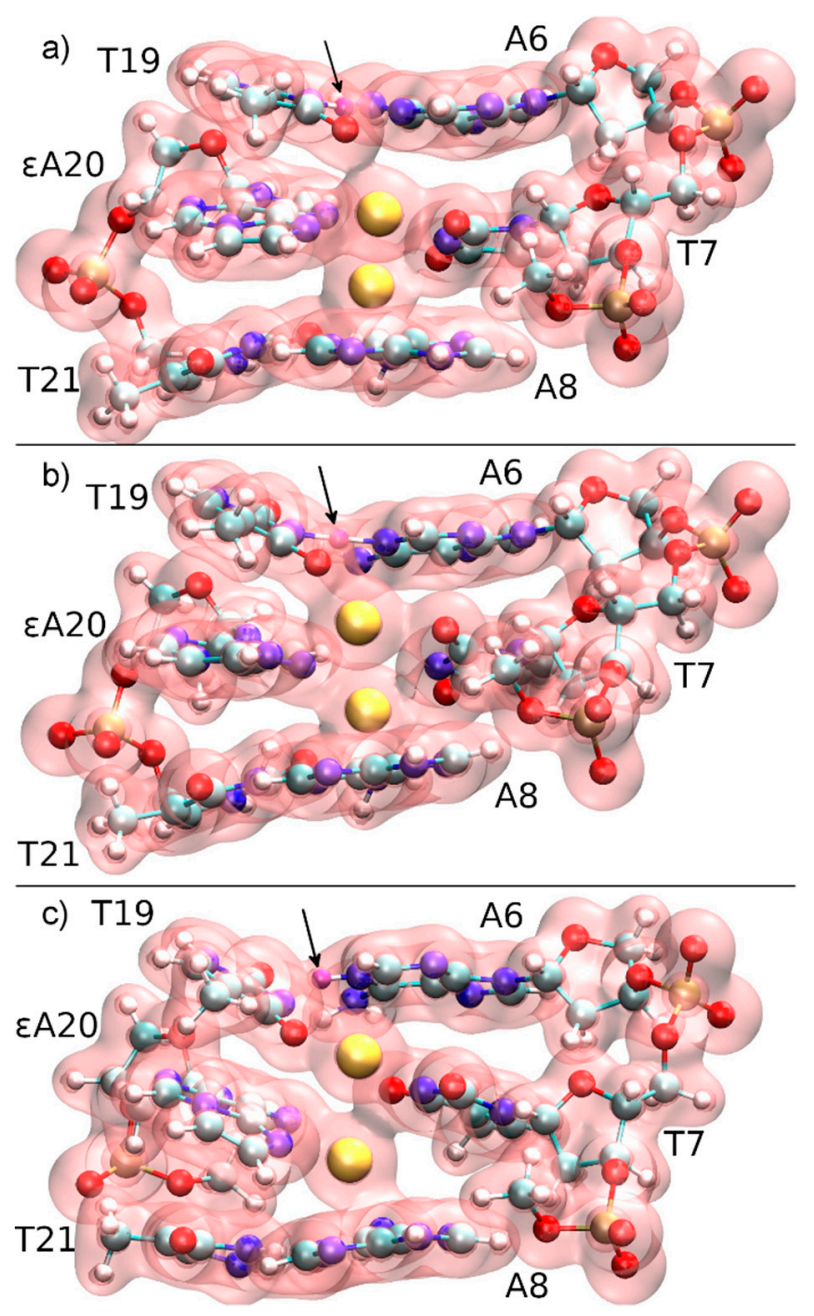

Figure 9. Total electron density of the three base pairs forming the quantum region, together with three phosphate groups neutralizing the subsystem of the constrained QM/MM molecular dynamics starting from structure 1 at $D_{\text {DNA }}=3.7 \AA$. The $\mathrm{N} 3 \mathrm{H}$ proton of T19, which is transferred to A6-N1, is marked with an arrow and coloured in purple. (a) $t=0 \mathrm{fs}$, the mercury ions (yellow) are initially located within the modified base pair, while $\mathrm{Hg} 2$ attracts the electron cloud from $\mathrm{T} 19$, thus favouring deprotonation. (b) $t=140 \mathrm{fs}$, proton transfer transition state. (c) $t=200 \mathrm{fs}$, the proton has been transferred to A6 and a T19-Hg(II)-T7 base pair is formed. 


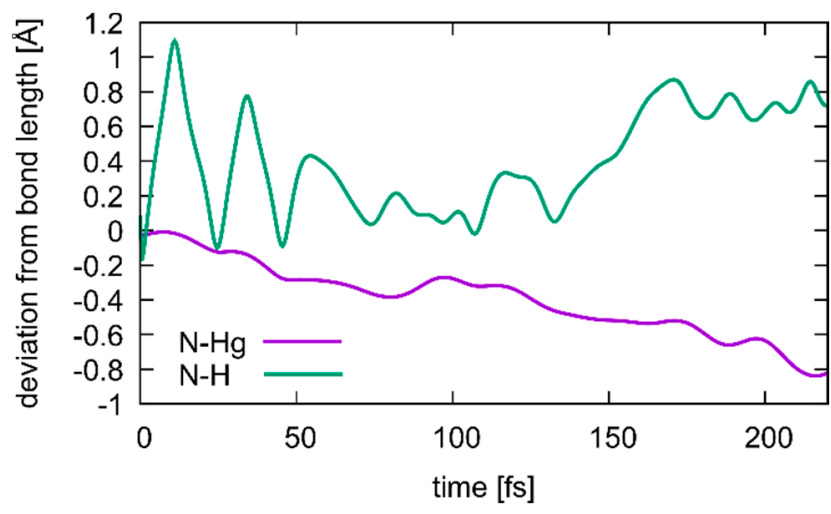

Figure 10. Changes in the $\mathrm{N} 3 \cdots \mathrm{H}$ (green) and $\mathrm{N} 3 \cdots \mathrm{Hg} 2$ (purple) distances during transition from structure 1 to structure 2 , where a deprotonation of T19 occurs simultaneous with the formation of a T19-Hg(II)-T7 base pair. Correlation between the two distances is visible, with the $\mathrm{Hg}$ ion closing in as the proton dissociates, until at 175 ps the $\mathbf{T} 19$ residue is fully deprotonated.

\subsubsection{Structure 3}

For comparison, an analogous DNA structure without any $\mathrm{Hg}$ ions (termed initial structure 3) was generated by deleting the $\mathrm{Hg}$ ions from initial structure 1, protonating the central thymine residue T7 (Figure 1b) and neutralizing the system by the addition of three counter ions. Then a geometry optimization was performed, followed by 500 ps of NPT-MD with settings given in Section 2.3. The resulting structure 3 is shown in Figure S8.

\subsection{Ab Initio Simulations of Isolated Base Pairs in Solution}

\subsubsection{Structure 4}

To have access to an all-QM calculation, the isolated modified base pair without $\mathrm{Hg}$ (Figure 1b) was solvated by 168 water molecules (Figure 11). The computational details are given in Section 2.3. The force field allowed for a 150 ps NPT equilibration simulation of the solvated base pair. This resulted in a unit cell of size $11.2 \AA \times 24.2 \AA \times 20.4 \AA$, corresponding to a density of $1037 \mathrm{~kg} / \mathrm{m}^{3}$. This geometry will be referred to as structure 4 .

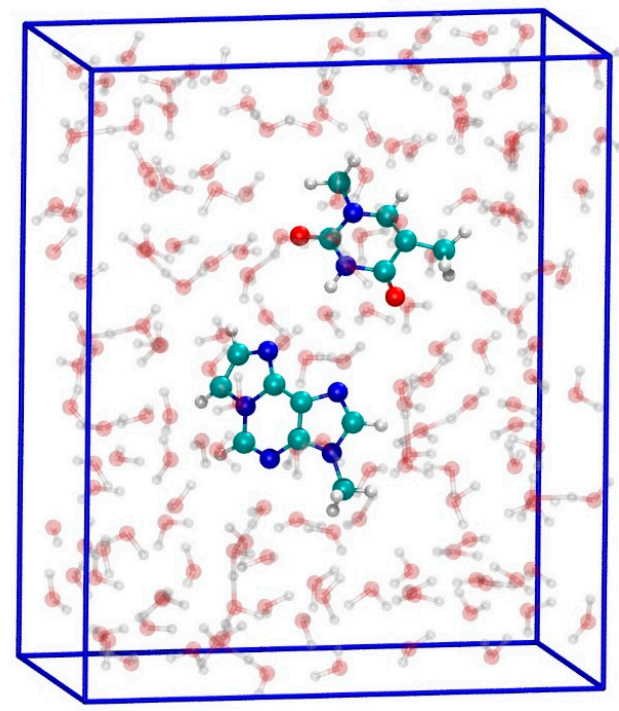
- Hydrogen
- Carbon
- Oxygen
- Nitrogen

Figure 11. Configuration for the QM dissociation MD of the isolated base pair T:EA (structure 4) with the MM-NPT equilibrated water box. 
Structure 4 was used as the initial geometry for an all-QM dissociation simulation of the isolated base pair without $\mathrm{Hg}$ ions in-between the bases.

\subsubsection{Structure 5}

Adding two $\mathrm{Hg}$ ions in-between the bases while removing the proton from T-N3 in structure 4 led to the initial structure for the dissociation simulation of the isolated mercurated base pair (structure 5).

\subsection{Free Energy Simulations}

Having generated these five different model systems, free energy simulations were performed to analyze the dissociation path and thus, using the principle of micro-reversibility, the formation path of the DNA duplex. QM/MM MD was performed with the settings outlined in Section 2.5 and the dynamic distance as defined in Section 2.6.1.

\section{Discussion}

\subsection{DNA Dissociation}

The calculated free energy profiles for DNA dissociation are presented in Figure 12. At the lowest energy dynamic distance of $D_{\mathrm{DNA}}=2.9 \AA$ of structure 1 , the average distance between the carbon atoms $\mathrm{C}^{\prime}$ of the deoxyribose attached to the nucleobases of the modified base pair is $10.4 \AA$. This is somewhat smaller than the experimental value of $11.4 \AA$ reported for a parallel-stranded duplex composed of A:T base pair in the reversed Watson-Crick geometry [86]. Within structure 2, where T19 was deprotonated and the $\mathrm{Hg}(\mathrm{II})$ ions were bound across different base layers, the free energy minimum is found at $D_{\mathrm{DNA}}=3.6 \AA$ with an average $C 1^{\prime} \ldots \mathrm{C} 1^{\prime}$ distance of $11.8 \AA$, which is closer to the experimental value. During the simulation of structure 2, both the NO and the NN bonding pattern are observed, with the system oscillating between the two minima (Figures 13 and 14). The first free energy minimum observed around $D_{\text {DNA }}=3.6 \AA$ arises because the amino groups of adenine residues $\mathbf{A} 6-\mathrm{N}_{6} \mathrm{H}_{2}$ and A8- $\mathrm{N}_{6} \mathrm{H}_{2}$ involved in one of the base pairs adjacent to the metal-mediated one stabilize the $\mathrm{Hg} 2$ ion in-between them.

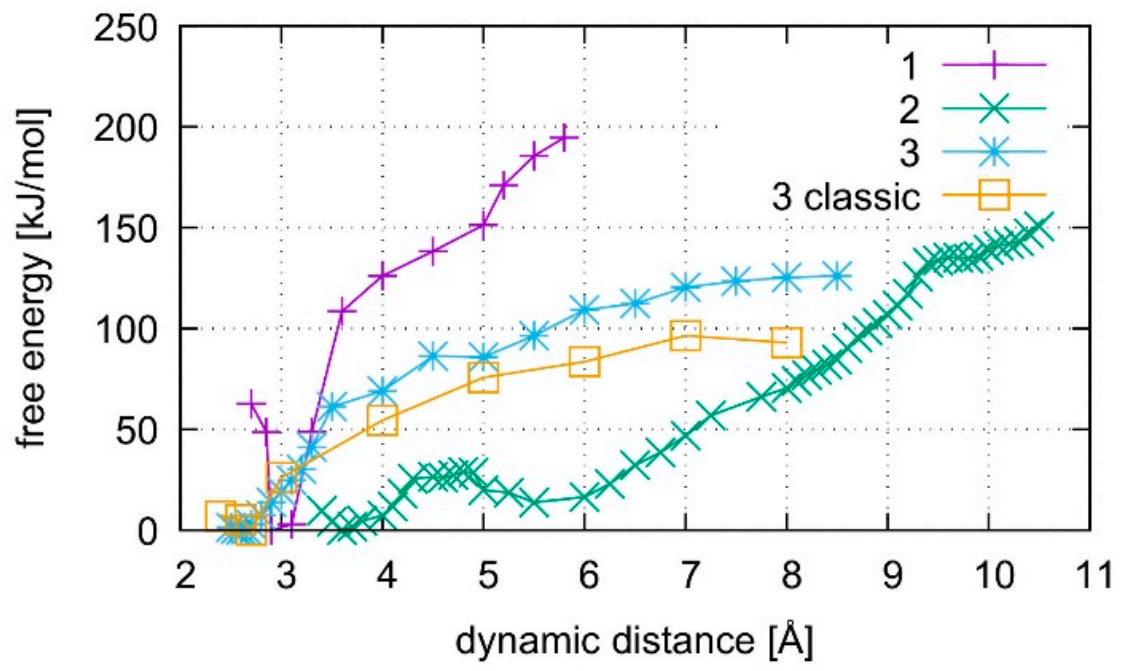

Figure 12. Comparison of free energies for the dissociation of structures $\mathbf{1}-\mathbf{3}$. Structures $\mathbf{1}$ and $\mathbf{2}$ contain the dinuclear $\mathrm{Hg}(\mathrm{II})$-mediated base pair, whereas structure 3 is the analogous mercury-free duplex. Structure 1 starts from a QMMM-optimized geometry, whereas structure 2 starts after QMMM-MD, and structure 3 is simulated by both classical and ab initio MD. 


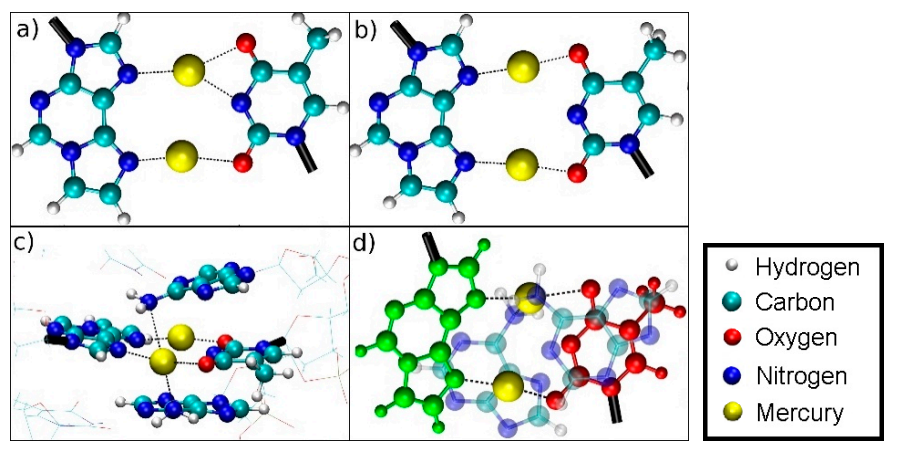

Figure 13. Oscillating bonding patterns of the metal-mediated base pair during the QM/MM MD of structure 2 at $D_{\mathrm{DNA}}=3.8 \AA$. Only the base pairs of interest are shown, with bonds to the backbone drawn in black. Water molecules are not displayed. (a) NN bonding pattern; (b) NO bonding pattern; (c) influence of the amino groups of adenine moieties A6 and A8 on Hg2; (d) view of situation c when rotated by $90^{\circ}$ with $\mathbf{T} 7$ drawn in red, $\varepsilon \mathbf{A} 20$ drawn in green with the $\mathrm{NH}_{2}$ groups of the neighbouring adenine $\mathbf{A} 6$ and $\mathbf{A} 8$ residues located on top and below $\mathrm{Hg} 2$.

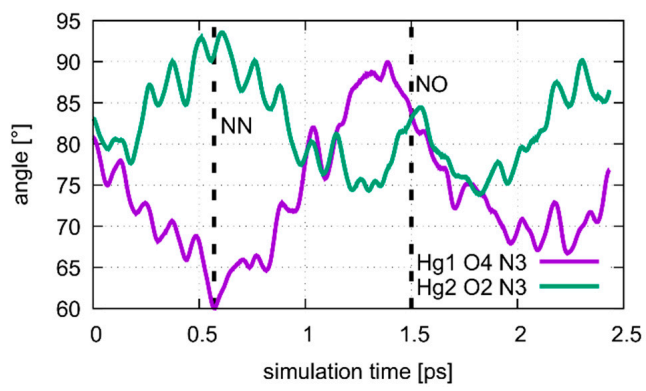

Figure 14. Dynamics of the $\mathrm{Hg} 1 \cdots \mathrm{T} 7 \mathrm{O} 4 \cdots \mathrm{T} 7 \mathrm{~N} 3$ and $\mathrm{Hg} 2 \cdots \mathrm{T} 7 \mathrm{O} 2 \cdots \mathrm{T} 7 \mathrm{~N} 3$ angles during the oscillation of patterns of the metal-mediated base pair during the QM/MM MD of structure 2 at $D_{\mathrm{DNA}}=3.8 \AA$. The NN pattern can be identified after 0.6 ps, corresponding to the situation in Figure 13a. At 1.5 ps the system is in the NO pattern, depicted in Figure 13b.

In all simulations, the modified base pair proved to be the weak spot of the DNA duplex, opening before the other base pairs. The bonding was found to be weakest if no mercury was incorporated into the DNA as can be seen from the free energy curves in Figure 12. As the dissociation simulation of structure 3 led to a breaking of the inner-pair hydrogen bonds of the artificial base pair (see Figure S3), the artificial base pair in case of structure 3 can be considered dissociated. For structures $\mathbf{1}$ and $\mathbf{2}$, only a change of bonding patterns occurred; thus, the DNA with $\mathrm{Hg}$ (II) can be considered more stable. To check for a possible influence of the classical force field parameters, the dissociation MD of structure 3 was repeated by a purely classical force-field approach. This was possible because no mercury ions are present in structure 3. Ten points along the trajectory of structure 3 were sampled for 55 ps, each, by classical MD.

Structure 1, where the calculations started from the optimized QM subsystem, emerges as the most stable structure, exhibiting the biggest energy gradient and thus the largest required force to promote the system out of its initial bonding pattern. It is followed by structure 2, which exhibits a second energy minimum along the dissociation path at $D_{\mathrm{DNA}}=5.5 \AA$. At this point, $\mathrm{Hg} 1$ is still located in the modified base pair, whereas $\mathrm{Hg} 2$ forms a diagonal T7-Hg(II)-T19 base pair involving nucleobases that were originally located in neighbouring base pairs. Such an unusual metal-mediated base pair was recently observed in a crystal structure, too [87]. This bonding pattern was enabled by deprotonation of T19, which is favoured by the presence of $\mathrm{Hg}(\mathrm{II})$ in the adjacent modified base pair. Structure 3 shows the weakest binding in the classical description. Its QM description led to lower binding energies than observed in the metal-mediated DNA duplexes. At $D_{\mathrm{DNA}}=8.5 \AA$, structure 3 opened a cavity at the modified base pair, allowing water to interact with the base pairs of the DNA duplex. 
All computed free energy differences lie in the range of 100-200 kJ/mol, which are typical binding energies of DNA base pairs [88]. These calculated energies correspond to the dissociation process depicted in Figures S1-S3 for the simulations of the whole DNA and to the binding energy of the isolated base pair in water from Section 4.2. As the simulated partial dissociation in the whole DNA mainly affects the modified base pair, the calculated energies are indicative of the amount of energy required to induce the observed change of bonding patterns within the modified base pair.

Within structures 1 and $\mathbf{2}$, the $\mathrm{Hg}(\mathrm{II})$ ions did not leave the DNA during the dissociation simulation, but changed their bonding pattern. However, structure 1 exhibited a dissociation path that allowed $\mathrm{Hg} 2$ to get into contact with water. This dissociation path can be analysed as follows. From the initial geometry of being situated within the modified base pair, the final geometries for structure $\mathbf{1}$ at $D_{\text {DNA }}=5.8 \AA$ showed $\mathrm{Hg} 2$ in an $\mathbf{A} 6-\mathrm{Hg}$ (II)- $\varepsilon \mathbf{A} 20$ environment (Figure 15a). The median distances from $\mathrm{Hg} 2$ to the coordinated nitrogen atoms are $2.15 \AA$ to $\varepsilon \mathbf{A} 20-\mathrm{N} 6$ and $2.17 \AA$ to $\mathbf{A} 6-\mathrm{N} 1$. $\mathrm{Hg} 1$ is involved in a $\mathbf{T} 7-\mathrm{Hg}(\mathrm{II})-\mathbf{A} 8$ pair dangling on the side of only one strand with a median distance from the coordinated nitrogen atoms to $\mathrm{Hg} 1$ of $2.17 \AA$ (T7-N3) and $2.12 \AA$ (A8-N6) (Figure 15b). These values suggest the formation of coordinate bonds to the $\mathrm{Hg}$ ions. $\mathrm{The}_{\mathrm{NH}}$ group of $\mathbf{A} 8$ changes its hybridization from a $s p^{2}$-like planar state to a $s p^{3}$-like tetrahedral state, with $\mathrm{Hg} 1$ acting as the fourth binding partner. Such a hybridization shift of the exocyclic amino group of adenine has been reported before in structurally characterized metal complexes [89].

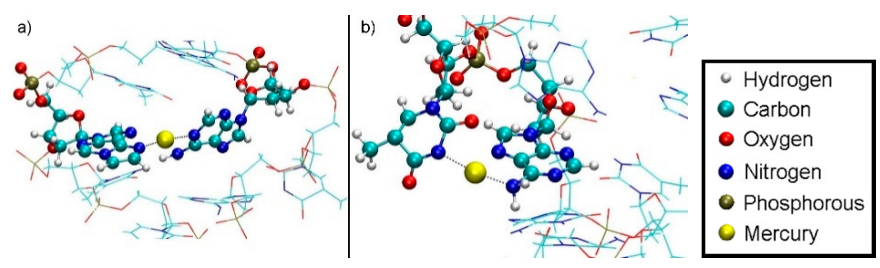

Figure 15. Section of final geometry of structure $\mathbf{1}$ at $D_{\mathrm{DNA}}=5.8 \AA$ with no water displayed. (a) $\mathrm{Hg} 2$ is bound between A6-N1 and $\varepsilon$ A20-N6 inside the double helix. (b) Hg1 is bound between T7-N3 and A8-N6 outside the double helix, with the N6 atom of adenine being hybridized in an $s p^{3}$-like state to engage in a coordinate bond with $\mathrm{Hg} 1$. The base pairs bulge of the DNA helix and are dangling in the water, thus forming a contact of the hydrophobic core to the water environment.

The dissociation MD of structure 2 proceeded to a final value of $D_{\mathrm{DNA}}=10.4 \AA$, when the quantum-mechanically treated $\mathrm{Hg} 1$ came into contact with classically treated water. At this point, $\mathrm{Hg} 2$ is involved in a T7- $\mathrm{Hg}(\mathrm{II})-\mathrm{T} 19$ pair, with equal $\mathrm{Hg}-\mathrm{N} 3$ distances of $2.15 \AA$ on either side (Figure 16a). In this structure, $\mathrm{Hg} 1$ is contained in an $\varepsilon \mathbf{A} 20-\mathrm{Hg}(\mathrm{II})-\mathbf{A} 8$ pair with median distances from the nitrogen atoms coordinated to $\mathrm{Hg}(\mathrm{II})$ of $2.20 \AA$ (A-N1) and $2.18 \AA$ ( $\varepsilon \mathbf{A}-\mathrm{N} 3)$, which are close to the distances found in the $\varepsilon \mathbf{A} 20-\mathrm{Hg}$ (II)- $\mathbf{A} 6$ base pair in structure $\mathbf{1}$. All distances suggest coordinate bonding of the $\mathrm{Hg}(\mathrm{II})$ ions (Figure $16 \mathrm{~b}$ ).

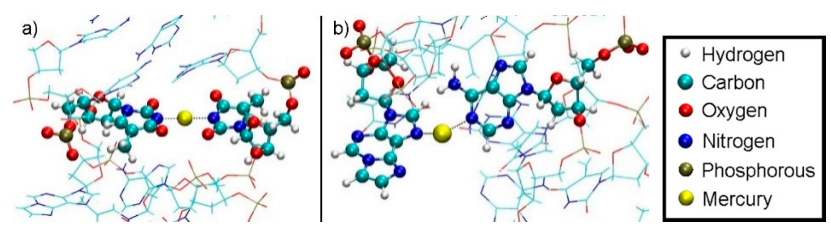

Figure 16. Final geometry of structure 2 at $D_{\mathrm{DNA}}=10.4 \AA$ with no water displayed. (a) $\mathrm{Hg} 2$ is bound between T19-N3 from the base pair originally adjacent the modified base and T7-N3 from the modified base pair. T19 transferred its N3-H proton to A6-N1 during the equilibration MD due to the presence of $\mathrm{Hg}(\mathrm{II})$. (b) Final geometry of structure 2 after thermodynamic integration at $D_{\mathrm{DNA}}=10.4 \AA$ with water not displayed. $\mathrm{Hg} 1$ is bound by A8-N1 from the base pair originally below the modified base and $\varepsilon$ A20-N7. 
The only migration of an $\mathrm{Hg}$ ion from the DNA inner core to the water solvent occurred in structure 1. The inverse of the pathway out of the DNA duplex can be considered a possible pathway into the duplex, using the principle of microscopic reversibility. The transition out of the DNA duplex is mediated by the exocyclic amino group of $\mathbf{A} 8-\mathrm{N}_{6} \mathrm{H}_{2}$ from the layer below the metal-mediated base pair. $\mathrm{Hg} 1$ approaches the $\mathrm{NH}_{2}$ group, thus leading to an $s p^{3}$-like hybridization of its nitrogen atom. Being attached to this moiety, which can rotate due to its single bond to the adenine, $\operatorname{Hg} 1$ can rotate out of the DNA core, while remaining attached to this group (Figure 17).

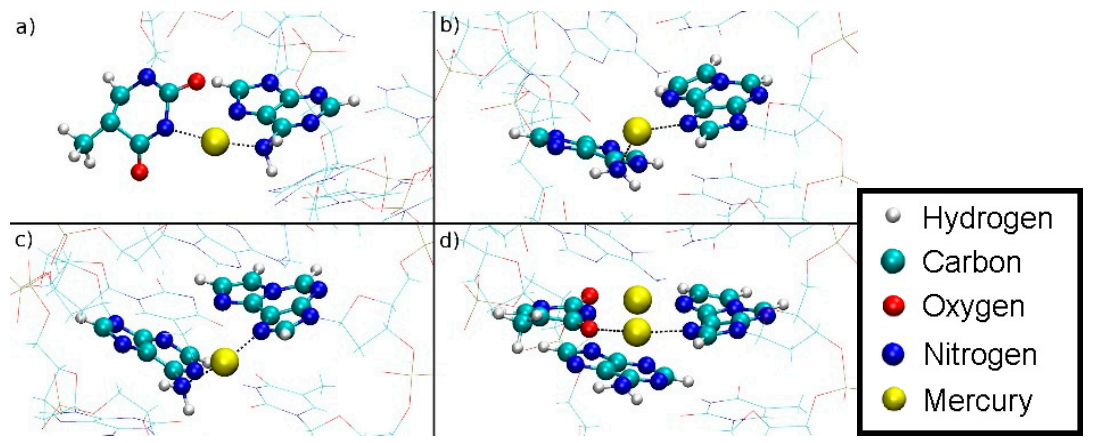

Figure 17. Simulated path of the Hg1 into the DNA duplex for structure 1 as derived from assuming microscopic reversibility of the dissociation of structure 1 . The $s p^{3}$-like hybridized amino group of $\mathbf{A} 8$ can clearly be discerned based on the orientation of its protons. (a) $D_{\mathrm{DNA}}=5.8 \AA \mathrm{Ag}$ (II) outside the DNA duplex in water, attached to the $\mathrm{NH}_{2}$ group of $\mathbf{A} 8$ and a dangling T7. (b) $D_{\mathrm{DNA}}=4.5 \AA$, the $\mathrm{NH}_{2}$ group is rotated about the C6-N6 bond and the $\mathrm{Hg}(\mathrm{II})$ is being attached to $\varepsilon \mathrm{A} 20$. (c) $D_{\mathrm{DNA}}=3.6 \AA$, further rotation of the $\mathrm{NH}_{2}$ group. (d) $D_{\mathrm{DNA}}=3.1 \AA$, inclusion of $\mathrm{Hg} 1$ into the metal-mediated base pair with $\mathrm{Hg} 2$ also shown. The $\mathrm{NH}_{2}$ group is now $s p^{2}$-hybridized.

The distance from Hg1 to A8-N6 is shown in Figure S9. During the rotation, the distance oscillates around at a mean value of $2.2 \AA$, while after the rotation, the $\mathrm{Hg}$ ion is coordinated by T7-O4 and EA20-N7 and the distance from $\mathrm{Hg} 1$ to A8-N6 reaches $2.8 \AA$, suggesting that the bond to the $\mathrm{NH}_{2}$ group is broken.

It is tempting to speculate that the relative location of the neighbouring adenine residue with respect to the $\varepsilon \mathbf{A}: \mathbf{T}$ mispair is important for the incorporation of the second $\mathrm{Hg}$ (II) ion into the dinuclear base pair. This would be in good agreement with the observation that only a mononuclear $\mathrm{Hg}$ (II)-mediated base pair is formed between $\varepsilon \mathbf{A}$ and $\mathbf{T}$ when the complementary sequences are arranged in an antiparallel-stranded manner, i.e., when the relative orientation of the neighbouring base pairs is different (see Supporting Information for details).

\subsection{Dissociation of the Isolated Base Pair}

The isolated $\varepsilon \mathbf{A}-\mathrm{Hg}(\mathrm{II})_{2}-\mathbf{T}$ base pair with $\mathrm{Hg}(\mathrm{II})$ ions incorporated (structure 5) exhibited a binding free energy of about $160 \mathrm{~kJ} / \mathrm{mol}$, while the isolated non-metal-modified base pair $\varepsilon \mathbf{A}: \mathbf{T}$ (structure 4) separated without any additional energy in a water environment (Figure 18). The latter can be explained by the fact that water molecules approaching from above or below have the propensity to form strong hydrogen bonding with the individual bases of the $\varepsilon \mathbf{A}-: \mathbf{T}$ pair, thus favouring dissociation (Figure 19b). Within the DNA helix, this effect is compensated by the hydrophobic inner DNA core, which blocks access of water from above or below, thus leading to a substantial binding energy of about $100 \mathrm{~kJ} / \mathrm{mol}$ $(\mathrm{MM})$ and $125 \mathrm{~kJ} / \mathrm{mol}(\mathrm{QM} / \mathrm{MM})$ for the non-metal-mediated DNA duplex (Figure 12). 


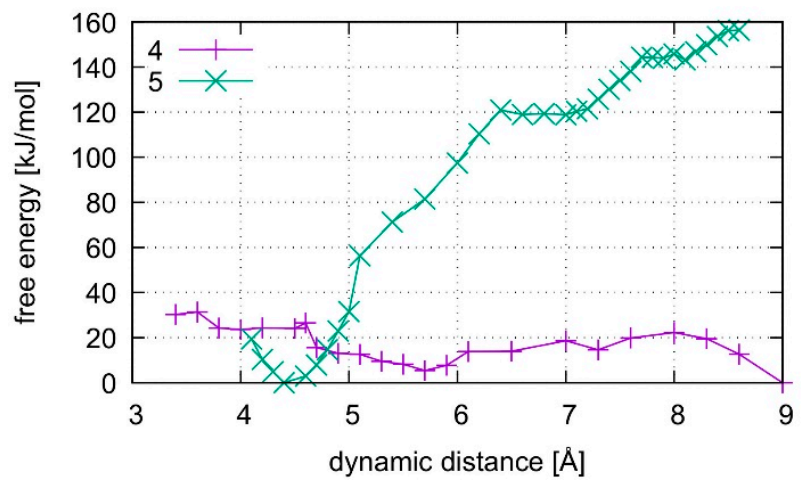

Figure 18. Comparison of the dissociation free energy in liquid water for the isolated T: $\varepsilon \mathbf{A}$ base pair where base pair 4 does not contain any $\mathrm{Hg}$ (II) ions whereas structure 5 is the dinuclear $\mathrm{Hg}$ (II)-mediated base pair. The introduction of $\mathrm{Hg}$ (II) leads to the formation of a metal-mediated base pair, whereas the $\mathrm{Hg}$ (II)-free base pair dissociates without the need of further energy.

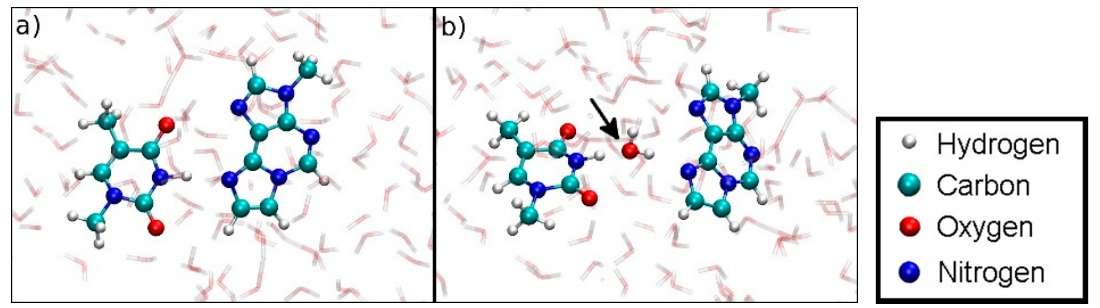

Figure 19. (a) Initial geometry at $D_{\mathrm{ISO}}=3.6 \AA$ of the dissociation $\mathrm{MD}$ for the $\mathrm{Hg}$ (II)-free hydrogen-bonded base pair (structure 4). (b) Dissociation is favoured due to the involvement of a water molecule in hydrogen bonding, which is not possible within a DNA duplex.

Along the dissociation path of structure 5, the dinuclear base pair splits up such that each base keeps an $\mathrm{Hg}$ (II) ion attached to it. $\mathrm{Hg} 1$ bonded to $\mathrm{T}-\mathrm{N} 3$ coordinates an additional $\mathrm{OH}^{-}$formed from a nearby water molecule. The former binding site of $\operatorname{Hg} 1$ at $\varepsilon \mathbf{A}$ is filled up by a hydrogen-bonded water molecule, pointing its oxygen atom towards $\mathrm{Hg} 2$. At $D_{\mathrm{ISO}}=8.6 \AA$, the attractive Coulomb interactions between the bases are screened by water molecules, facilitating further dissociation (Figure 20).

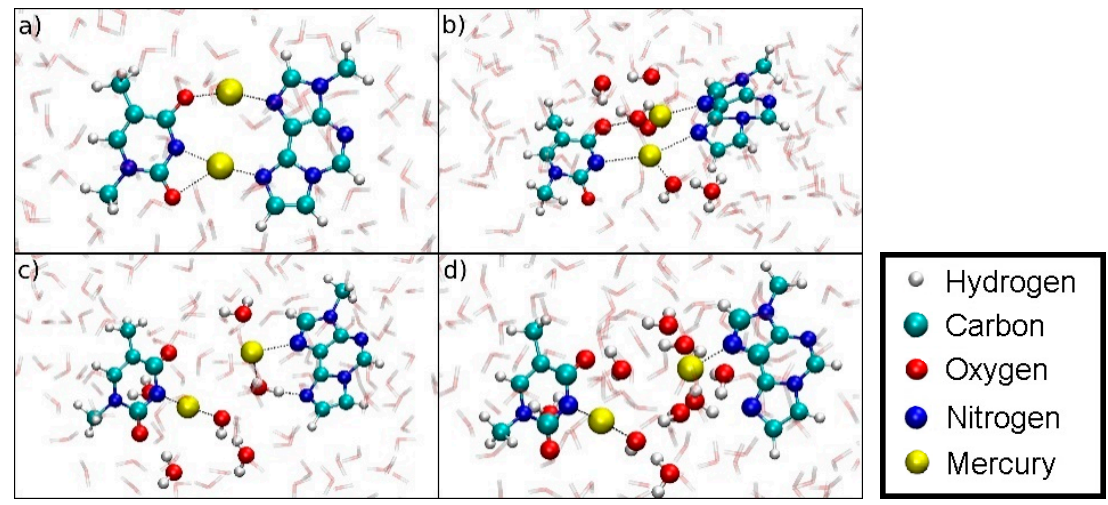

Figure 20. Snapshots of the dissociation MD for the metal-mediated base pair (structure 5). (a) $D_{\text {ISO }}=4.4 \AA$, initial geometry. (b) $D_{\text {ISO }}=6.4 \AA$, formation of an $\mathrm{H}_{3} \mathrm{O}^{+}$and an $\mathrm{OH}^{-}$close to Hg2. (c) $D_{\text {ISO }}=7.3 \AA$, coordination of a water molecule at the former $\varepsilon$ A-N6 binding site of $\mathrm{Hg}$, while the $\mathrm{OH}^{-}$coordinates the T-N3-bonded Hg1. (d) $D_{\text {ISO }}=8.6 \AA$, final geometry of the dissociation MD. Hg1 remains attached to T-N3 and carries an additional $\mathrm{OH}^{-}$ligand, $\mathrm{Hg} 2$ binds $\varepsilon \mathrm{A}-\mathrm{N} 7$, while the water molecules form a bridge with their oxygen atoms pointing towards to the positively charged $\mathrm{Hg}(\mathrm{II})$ and their protons facing the electronegative $\mathrm{O}$ and $\mathrm{N}$ atoms of the nucleobases. 


\section{Conclusions}

Free energy QM and QMMM molecular dynamics simulations have been performed of an experimentally established parallel-stranded DNA duplex bearing a $\mathbf{T}-\mathrm{Hg}(\mathrm{II})_{2}-\varepsilon \mathbf{A}$ base pair. Two main bonding patterns have been identified for the mercury(II)-mediated base pair. For the most stable structure 2, the $\mathrm{C}^{\prime}{ }^{\prime} \ldots \mathrm{C}^{\prime}$ distance of the carbon atoms involved in the glycosidic bonds is close to the experimental value derived from a related experimental structure [86]. While the isolated nucleobases $\mathbf{T}$ and $\varepsilon \mathbf{A}$ do not form a base pair in the absence of $\mathrm{Hg}$ (II), the inclusion of $\mathrm{Hg}$ (II) leads to a stable dinuclear metal-mediated base pair. If neighbouring base pairs are considered in the calculations, the amino groups of their adenine nucleobases influence the bonding pattern by binding to the $\mathrm{Hg}$ (II) from above and below. This unexpected structural insight shows that the precise location of a metal ion within a metal-mediated base pair is not necessarily identical to that in the ideal geometry of the isolated base pair but may also depend on the identity of the adjacent canonical base pairs.

In the complete DNA duplex, the artificial base pair proved to be the weak point in both classical and quantum mechanics simulations if no $\mathrm{Hg}$ (II) is incorporated. Upon to the incorporation of $\mathrm{Hg}$ (II), the base pair is strengthened. In the dissociation simulations of the $\mathrm{Hg}$ (II)-bound DNA duplex, a shift in bonding patterns is observed, with the $\mathrm{Hg}(\mathrm{II})$ ions engaging in the original $\mathbf{T}-\mathrm{Hg}(\mathrm{II})_{2}-\varepsilon \mathbf{A}$ base pair, in an inter-planar $\mathbf{T}-\mathrm{Hg}(\mathrm{II})-\mathbf{T}$ base pair, or in an unprecedented $\mathbf{A}-\mathrm{Hg}(\mathrm{II})-\varepsilon \mathbf{A}$ base pair. Irrespective of the precise coordination environment of the $\mathrm{Hg}$ (II) ions, the $\mathrm{Hg}$ (II)-containing DNA is predicted to be more stable than its non-metalated counterpart.

During one simulation, a mercury ion was transferred from the inner DNA region to the surrounding water, where the amino group of an adjacent adenine moiety acted as a turnstile to transport the mercury(II) ion out of the DNA. Due to the principle of microscopic reversibility, this adenine residue can be postulated to act as a gateway for $\mathrm{Hg}$ (II) during the formation of the metal-mediated base pair. This indicates another important contribution of the oligonucleotide sequence on the mechanism of metal-mediated base pair formation, which will need to be investigated in detail in future experiments. This is in good agreement with the experimental observation that in a different sequence context, only one $\mathrm{Hg}$ (II) is incorporated into the $\boldsymbol{\varepsilon} \mathbf{A}: \mathbf{T}$ pair. The present results may thus prove useful in guiding the future design of $\mathrm{Hg}$-modified DNA.

As $\mathrm{Hg}(\mathrm{II})$ has a linear coordination environment, the findings of this paper concerning the structural arrangement can only be transferred to metal ions which coordinate linearly, which is not the case for the other metal ions mentioned in the introduction, except for Ag(I). Similarly, they are not applicable to $\operatorname{Ag}(\mathrm{I})$, because as a monovalent cation it is less capable of deprotonating aqua ligands to hydroxido ligands. However, the observed turnstile mechanism might be relevant to the incorporation of other metal cations into DNA, as they can bind to the lone electron pair of the adenine amino group.

Aside from the chemical insights gained, it is worth noting that the dynamic distance constraint proved to be a useful method to investigate bonding patterns in systems with competing (hydrogen) bonds-not only for quantitative free energy simulations, but also for constructing DNA geometries with predefined hydrogen bonding patterns. Since this is a common issue in the investigation of solvated biomolecules, the current approach should also be helpful for many other systems.

Supplementary Materials: The following are available online, Figure S1: Final geometry of structure 1, Figure S2: Final geometry of structure 2, Figure S3: Final geometry of structure 3, Figure S4: Lagrange multipliers for path 1, Figure S5: Lagrange multipliers for path 2, Figure S6: Lagrange multipliers for path 3, Figure S7: Energies and end-to-end distances of optimized geometries for different functionals, Figure S8: DNA structure without $\mathrm{Hg}$, Figure S9: A8-N6 $\cdots \mathrm{Hg}(\mathrm{II})$ distance, PDB structure of the DNA, topology of the DNA for use in CP2K, Cartesian coordinates corresponding to Figures 4 and 5.

Author Contributions: Conceptualization, J.M., N.L.D. and J.B.; methodology, J.B. and N.L.D.; validation, J.M. and N.L.D.; formal analysis, J.B.; investigation, J.B and I.S.; writing-original draft preparation, J.B.; writing-review and editing, J.B., N.L.D. and J.M.; visualization, J.B.; supervision, N.L.D and J.M.; project administration, N.L.D. and J.M.; funding acquisition, N.L.D. and J.M. All authors have read and agreed to the published version of the manuscript. 
Funding: Financial support by the Deutsche Forschungsgemeinschaft (SFB 858, projects B09 and Z01) is gratefully acknowledged.

Acknowledgments: The simulations were carried out at the High Performance Computing facility PALMA at the Westfälische Wilhelms-Universität Münster.

Conflicts of Interest: The authors declare no conflict of interest.

\section{References}

1. Stulz, E.; Clever, G.H. DNA in Supramolecular Chemistry and Nanotechnology; John Wiley \& Sons: Chichester, UK, 2015.

2. Jash, B.; Müller, J. Metal-Mediated Base Pairs: From Characterization to Application. Chem. Eur. J. 2017, 23, 17166-17178. [CrossRef]

3. Takezawa, Y.; Müller, J.; Shionoya, M. Artificial DNA Base Pairing Mediated by Diverse Metal Ions. Chem. Lett. 2017, 46, 622-633. [CrossRef]

4. Kondo, J.; Yamada, T.; Hirose, C.; Okamoto, I.; Tanaka, Y.; Ono, A. Crystal Structure of Metallo DNA Duplex Containing Consecutive Watson-Cric-klike T-HgII-T Base Pairs. Angew. Chem. Int. Ed. 2014, 53, 2385-2388. [CrossRef] [PubMed]

5. Dairaku, T.; Furuita, K.; Sato, H.; Šebera, J.; Nakashima, K.; Kondo, J.; Yamanaka, D.; Kondo, Y.; Okamoto, I.; Ono, A.; et al. Structure Determination of an $\mathrm{Ag}^{\mathrm{I}}$-Mediated Cytosine-Cytosine Base Pair within DNA Duplex in Solution with ${ }^{1} \mathrm{H} /{ }^{15} \mathrm{~N} /{ }^{109} \mathrm{Ag}$ NMR Spectroscopy. Chem. Eur. J. 2016, 22, 13028-13031. [CrossRef] [PubMed]

6. Schmidt, O.P.; Jurt, S.; Johannsen, S.; Karimi, A.; Sigel, R.K.O.; Luedtke, N.W. Concerted dynamics of metallo-base pairs in an A/B-form helical transition. Nat. Commun. 2019, 10, 4818. [CrossRef] [PubMed]

7. Tanaka, Y.; Kondo, J.; Sychrovský, V.; Šebera, J.; Dairaku, T.; Saneyoshi, H.; Urata, H.; Torigoe, H.; Ono, A. Structures, physicochemical properties, and applications of $\mathrm{T}-\mathrm{Hg} \mathrm{II}-\mathrm{T}, \mathrm{C}-\mathrm{Ag} \mathrm{I}-\mathrm{C}$, and other metallo-base-pairs. Chem. Commun. 2015, 51, 17343-17360. [CrossRef] [PubMed]

8. Naskar, S.; Müller, J. Light-induced formation of thymine-containing mercury(II)-mediated base pairs. Chem. Eur. J. 2019, 25, 16214-16218. [CrossRef] [PubMed]

9. Naskar, S.; Hebenbrock, M.; Müller, J. Light-induced formation of silver(I)-mediated base pairs in DNA: Possibilities and limitations. Inorg. Chim. Acta 2020, 512, 119856. [CrossRef]

10. Tanaka, K.; Tengeiji, A.; Kato, T.; Toyama, N.; Shionoya, M. A Discrete Self-Assembled Metal Array in Artificial DNA. Science 2003, 299, 1212-1213. [CrossRef]

11. Clever, G.H.; Polborn, K.; Carell, T. A Highly DNA-Duplex-Stabilizing Metal-Salen Base Pair. Angew. Chem. Int. Ed. 2005, 44, 7204-7208. [CrossRef]

12. Sandmann, N.; Defayay, D.; Hepp, A.; Müller, J. Metal-mediated base pairing in DNA involving the artificial nucleobase imidazole-4-carboxylate. J. Inorg. Biochem. 2019, 191, 85-93. [CrossRef] [PubMed]

13. Sandmann, N.; Bachmann, J.; Hepp, A.; Doltsinis, N.L.; Müller, J. Copper(II)-mediated base pairing involving the artificial nucleobase 3H-imidazo[4,5-f] quinolin-5-ol. Dalton Trans. 2019, 48, 10505-10515. [CrossRef]

14. Jash, B.; Müller, J. Stable Copper(I)-Mediated Base Pairing in DNA. Angew. Chem. Int. Ed. 2018, 57, 9524-9527. [CrossRef] [PubMed]

15. Clever, G.H.; Carell, T. Controlled Stacking of 10 Transition-Metal Ions inside a DNA Duplex. Angew. Chem. Int. Ed. 2007, 46, 250-253. [CrossRef] [PubMed]

16. Switzer, C.; Sinha, S.; Kim, P.H.; Heuberger, B.D. A Purine-like Nickel(II) Base Pair for DNA. Angew. Chem. Int. Ed. 2005, 44, 1529-1532. [CrossRef] [PubMed]

17. Jash, B.; Müller, J. A stable zinc(II)-mediated base pair in a parallel-stranded DNA duplex. J. Inorg. Biochem. 2018, 186, 301-306. [CrossRef]

18. Takezawa, Y.; Nishiyama, K.; Mashima, T.; Katahira, M.; Shionoya, M. Bifacial Base-Pairing Behaviors of 5-Hydroxyuracil DNA Bases through Hydrogen Bonding and Metal Coordination. Chem. Eur. J. 2015, 21, 14713-14716. [CrossRef]

19. Räisälä, H.; Lönnberg, T. Covalently Palladated Oligonucleotides Through Oxidative Addition of $\operatorname{Pd}^{0}$. Chem. Eur. J. 2019, 25, 4751-4756. [CrossRef]

20. Escher, D.; Müller, J. Silver(I) coordination in silver(I)-mediated homo base pairs of 6-pyrazolylpurine in DNA duplexes involves the Watson-Crick edge. Chem. Eur. J. 2020, 26. [CrossRef] 
21. Schönrath, I.; Tsvetkov, V.B.; Zatsepin, T.S.; Aralov, A.V.; Müller, J. Silver(I)-mediated base pairing in parallel-stranded DNA involving the luminescent cytosine analog 1,3-diaza-2-oxophenoxazine. J. Biol. Inorg. Chem. 2019, 24, 693-702. [CrossRef]

22. Ukale, D.U.; Tähtinen, P.; Lönnberg, T. 1,8-Dimercuri-6-Phenyl-1H-Carbazole as a Monofacial Dinuclear Organometallic Nucleobase. Chem. Eur. J. 2020, 26, 2164-2168. [CrossRef]

23. Méndez-Arriaga, J.M.; Maldonado, C.R.; Dobado, J.A.; Galindo, M.A. Silver(I)-Mediated Base Pairs in DNA Sequences Containing 7-Deazaguanine/Cytosine: Towards DNA with Entirely Metallated Watson-Crick Base Pairs. Chem. Eur. J. 2018, 24, 4583-4589. [CrossRef] [PubMed]

24. Santamaría-Díaz, N.; Méndez-Arriaga, J.M.; Salas, J.M.; Galindo, M.A. Highly Stable Double-Stranded DNA Containing Sequential Silver(I)-Mediated 7-Deazaadenine/Thymine Watson-Crick Base Pairs. Angew. Chem. Int. Ed. 2016, 55, 6170-6174. [CrossRef] [PubMed]

25. Zhou, X.; Kondhare, D.; Leonard, P.; Seela, F. Anomeric 5-Aza-7-deaza-2'-deoxyguanosines in Silver-Ion-Mediated Homo and Hybrid Base Pairs: Impact of Mismatch Structure, Helical Environment, and Nucleobase Substituents on DNA Stability. Chem. Eur. J. 2019, 25, 10408-10419. [CrossRef]

26. Guo, X.; Leonard, P.; Ingale, S.A.; Liu, J.; Mei, H.; Sieg, M.; Seela, F. 5-Aza-7-deaza-2'-deoxyguanosine and 2'-Deoxycytidine Form Programmable Silver-Mediated Base Pairs with Metal Ions in the Core of the DNA Double Helix. Chem. Eur. J. 2018, 24, 8883-8892. [CrossRef]

27. Zhao, H.; Leonard, P.; Guo, X.; Yang, H.; Seela, F. Silver-Mediated Base Pairs in DNA Incorporating Purines,7-Deazapurines, and 8-Aza-7-deazapurines: Impact of Reduced Nucleobase Binding Sites and an Altered Glycosylation Position. Chem. Eur. J. 2017, 23, 5529-5540. [CrossRef]

28. Liu, S.; Clever, G.H.; Takezawa, Y.; Kaneko, M.; Tanaka, K.; Guo, X.; Shionoya, M. Direct Conductance Measurement of Individual Metallo-DNA Duplexes within Single-Molecule Break Junctions. Angew. Chem. Int. Ed. 2011, 50, 8886-8890. [CrossRef]

29. Ehrenschwender, T.; Schmucker, W.; Wellner, C.; Augenstein, T.; Carl, P.; Harmer, J.; Breher, F.; Wagenknecht, H.-A. Development of a Metal-Ion-Mediated Base Pair for Electron Transfer in DNA. Chem. Eur. J. 2013, 19, 12547-12552. [CrossRef]

30. Al-Mahamad, L.L.G.; El-Zubir, O.; Smith, D.G.; Horrocks, B.R.; Houlton, A. A coordination polymer for the site-specific integration of semiconducting sequences into DNA-based materials. Nat. Commun. 2017, 8, 720. [CrossRef]

31. Léon, J.C.; She, Z.; Kamal, A.; Shamsi, M.H.; Müller, J.; Kraatz, H.-B. DNA Films Containing the Artificial Nucleobase Imidazole Mediate Charge Transfer in a Silver(I)-Responsive Way. Angew. Chem. Int. Ed. 2017, 56, 6098-6102. [CrossRef]

32. Hensel, S.; Eckey, K.; Scharf, P.; Megger, N.; Karst, U.; Müller, J. Excess Electron Transfer through DNA Duplexes Comprising a Metal-Mediated Base Pair. Chem. Eur. J. 2017, 23, 10244-10248. [CrossRef] [PubMed]

33. Nakama, T.; Takezawa, Y.; Sasaki, D.; Shionoya, M. Allosteric Regulation of DNAzyme Activities through Intrastrand Transformation Induced by Cu(II)-Mediated Artificial Base Pairing. J. Am. Chem. Soc. 2020, 142, 10153-10162. [CrossRef] [PubMed]

34. Takezawa, Y.; Nakama, T.; Shionoya, M. Enzymatic Synthesis of Cu(II)-Responsive Deoxyribozymes through Polymerase Incorporation of Artificial Ligand-Type Nucleotides. J. Am. Chem. Soc. 2019, 141, 19342-19350. [CrossRef] [PubMed]

35. Takezawa, Y.; Yoneda, S.; Duprey, J.-L.H.A.; Nakama, T.; Shionoya, M. Metal-responsive structural transformation between artificial DNA duplexes and three-way junctions. Chem. Sci. 2016, 7, 3006-3010. [CrossRef]

36. Léon, J.C.; González-Abradelo, D.; Strassert, C.A.; Müller, J. Fluorescent DNA-Templated Silver Nanoclusters from Silver(I)-Mediated Base Pairs. Chem. Eur. J. 2018, 24, 8320-8324. [CrossRef]

37. Taherpour, S.; Golubev, O.; Lönnberg, T. On the feasibility of recognition of nucleic acid sequences by metal-ion-carrying oligonucleotides. Inorg. Chim. Acta 2016, 452, 43-49. [CrossRef]

38. Jash, B.; Müller, J. Application of a Metal-Mediated Base Pair to the Detection of Medicinally Relevant Single Nucleotide Polymorphisms. Eur. J. Inorg. Chem. 2017, 3857-3861. [CrossRef]

39. Jash, B.; Scharf, P.; Sandmann, N.; Fonseca Guerra, C.; Megger, D.A.; Müller, J. A metal-mediated base pair that discriminates between the canonical pyrimidine nucleobases. Chem. Sci. 2017, 8, 1337-1343. [CrossRef]

40. Müller, J. Nucleic acid duplexes with metal-mediated base pairs and their structures. Coord. Chem. Rev. 2019, 393, 37-47. [CrossRef] 
41. Funai, T.; Miyazaki, Y.; Aotani, M.; Yamaguchi, E.; Nakagawa, O.; Wada, S.-i.; Torigoe, H.; Ono, A.; Urata, H. $\mathrm{Ag}^{\mathrm{I}}$ Ion Mediated Formation of a C-A Mispair by DNA Polymerases. Angew. Chem. Int. Ed. 2012, 51, 6464-6466. [CrossRef]

42. Funai, T.; Nakamura, J.; Miyazaki, Y.; Kiriu, R.; Nakagawa, O.; Wada, S.-I.; Ono, A.; Urata, H. Regulated Incorporation of Two Different Metal Ions into Programmed Sites in a Duplex by DNA Polymerase Catalyzed Primer Extension. Angew. Chem. Int. Ed. 2014, 53, 6624-6627. [CrossRef] [PubMed]

43. Kobayashi, T.; Takezawa, Y.; Sakamoto, A.; Shionoya, M. Enzymatic synthesis of ligand-bearing DNAs for metal-mediated base pairing utilising a template-independent polymerase. Chem. Commun. 2016, 52, 3762-3765. [CrossRef] [PubMed]

44. Kaul, C.; Müller, M.; Wagner, M.; Schneider, S.; Carell, T. Reversible bond formation enables the replication and amplification of a crosslinking salen complex as an orthogonal base pair. Nat. Chem. 2011, 3, 794-800. [CrossRef] [PubMed]

45. Flamme, M.; Levi-Acobas, F.; Hensel, S.; Naskar, S.; Röthlisberger, P.; Sarac, I.; Gasser, G.; Müller, J.; Hollenstein, M. Effect of metal shielding on the enzymatic construction of artificial base pairs. ChemBioChem 2020, 21. [CrossRef] [PubMed]

46. Röthlisberger, P.; Levi-Acobas, F.; Sarac, I.; Marlière, P.; Herdewijn, P.; Hollenstein, M. Towards the enzymatic formation of artificial metal base pairs with a carboxy-imidazole-modified nucleotide. J. Inorg. Biochem. 2019, 191, 154-163. [CrossRef] [PubMed]

47. Röthlisberger, P.; Levi-Acobas, F.; Sarac, I.; Marlière, P.; Herdewijn, P.; Hollenstein, M. On the enzymatic incorporation of an imidazole nucleotide into DNA. Org. Biomol. Chem. 2017, 15, 4449-4455. [CrossRef] [PubMed]

48. Okamoto, I.; Ono, T.; Sameshima, R.; Ono, A. Metal ion-binding properties of DNA duplexes containing thiopyrimidine base pairs. Chem. Commun. 2012, 48, 4347-4349. [CrossRef]

49. Mandal, S.; Hepp, A.; Müller, J. Unprecedented dinuclear silver(I)-mediated base pair involving the DNA lesion 1,N6-ethenoadenine. Dalton Trans. 2015, 44, 3540-3543. [CrossRef]

50. Mandal, S.; Hebenbrock, M.; Müller, J. Relative Strand Orientation in a DNA Duplex Controls the Nuclearity of a Metal-Mediated Base Pair. Chem. Eur. J. 2017, 23, 5962-5965. [CrossRef]

51. Fujii, A.; Nakagawa, O.; Kishimoto, Y.; Okuda, T.; Nakatsuji, Y.; Nozaki, N.; Kasahara, Y.; Obika, S. 1,3,9-Triaza-2-oxophenoxazine artificial nucleobase forms highly stable self-base pairs with three $\mathrm{Ag}^{\mathrm{I}}$ ions in a duplex. Chem. Eur. J. 2019, 25, 7443-7448. [CrossRef]

52. Mandal, S.; Hebenbrock, M.; Müller, J. A Dinuclear Mercury(II)-Mediated Base Pair in DNA. Angew. Chem. Int. Ed. 2016, 55, 15520-15523. [CrossRef] [PubMed]

53. Müller, J. Metal-mediated base pairs in parallel-stranded DNA. Beilstein J. Org. Chem. 2017, 13, $2671-2681$. [CrossRef]

54. Onyido, I.; Norris, A.R.; Buncel, E. Biomolecule-Mercury Interactions: Modalities of DNA Base-Mercury Binding Mechanisms. Remediation Strategies. Chem. Rev. 2004, 104, 5911-5929. [CrossRef]

55. Burisch, C.; Markwick, P.R.L.; Doltsinis, N.L.; Schlitter, J. 'Dynamic Distance' Reaction Coordinate for Competing Bonds: Applications in Classical and Ab Initio Simulations. J. Chem. Theory Comput. 2008, 4, 164-172. [CrossRef] [PubMed]

56. Frisch, M.J.; Trucks, G.W.; Schlegel, H.B.; Scuseria, G.E.; Robb, M.A.; Cheeseman, J.R.; Scalmani, G.; Barone, V.; Mennucci, B.; Petersson, G.A.; et al. Gaussian 09, Revision D.01; Gaussian, Inc.: Wallingford, CK, USA, 2013.

57. Perdew, J.P.; Burke, K.; Ernzerhof, M. Generalized Gradient Approximation Made Simple. Phys. Rev. Lett. 1996, 77, 3865-3868. [CrossRef]

58. Perdew, J.P.; Ernzerhof, M.; Burke, K. Rationale for mixing exact exchange with density functional approximations. J. Chem. Phys. 1996, 105, 9982-9985. [CrossRef]

59. Adamo, C.; Barone, V. Toward reliable density functional methods without adjustable parameters: The PBE0 model. J. Chem. Phys. 1999, 110, 6158-6170. [CrossRef]

60. Ernzerhof, M.; Scuseria, G.E. Assessment of the Perdew-Burke-Ernzerhof exchange-correlation functional. J. Chem. Phys. 1999, 110, 5029-5036. [CrossRef]

61. Dunning, T.H., Jr.; Hay, P.J. Modern Theoretical Chemistry; Schaefer, H.F., III, Ed.; Plenum: New York, NY, USA, 1977; Volume 3, pp. 1-28.

62. Andrae, D.; Häußermann, U.; Dolg, M.; Stoll, H.; Preuß, H. Energy-adjusted ab initio pseudopotentials for the second and third row transition elements. Theor. Chim. Acta 1990, 77, 123-141. [CrossRef] 
63. Grimme, S.; Ehrlich, S.; Goerigk, L. Effect of the Damping Function in Dispersion Corrected Density Functional Theory. J. Comput. Chem. 2011, 32, 1456-1465. [CrossRef]

64. Grimme, S.; Antony, J.; Ehrlich, S.; Krieg, H. A consistent and accurate ab initio parametrization of density functional dispersion correction (DFT-D) for the 94 elements H-Pu. J. Chem. Phys. 2010, 132, 154104. [CrossRef] [PubMed]

65. Cossi, M.; Barone, V.; Cammi, R.; Tomasi, J. Ab initio study of solvated molecules: A new implementation of the polarizable continuum model. Chem. Phys. Lett. 1996, 255, 327-335. [CrossRef]

66. Neese, F. The ORCA program system. WIREs Comput. Mol. Sci. 2012, 2, 73-78. [CrossRef]

67. Van Lenthe, E.; Snijders, J.G.; Baerends, E.J. The zero-order regular approximation for relativistic effects: The effect of spin-orbit coupling in closed shell molecules. J. Chem. Phys. 1996, 105, 6505-6516. [CrossRef]

68. Pantazis, D.A.; Chen, X.-Y.; Landis, C.R.; Neese, F. All-Electron Scalar Relativistic Basis Sets for Third-Row Transition Metal Atoms. J. Chem. Theory Comput. 2008, 4, 908-919. [CrossRef]

69. Case, D.A.; Ben-Shalom, I.Y.; Brozell, S.R.; Cerutti, D.S.; Cheatham III, T.E.; Cruzeiro, V.W.D.; Darden, T.A.; Duke, R.E.; Ghoreishi, D.; Gilson, M.K.; et al. AMBER 2018; University of California: San Francisco, CA, USA, 2018.

70. Ivani, I.; Dans, P.D.; Noy, A.; Pérez, A.; Faustino, I.; Hospital, A.; Walther, J.; Andrio, P.; Goñi, R.; Balaceanu, A.; et al. Parmbsc1: A refined force field for DNA simulations. Nat. Methods 2016, 13, 55-58. [CrossRef]

71. Fuchs, J.-F.; Nedev, H.; Poger, D.; Ferrand, M.; Brenner, V.; Dognon, J.-P.; Crouzy, S. New model potentials for sulfur-copper(I) and sulfur-mercury(II) interactions in proteins: From ab initio to molecular dynamics. J. Comput. Chem. 2006, 27, 837-856. [CrossRef]

72. Bayly, C.I.; Cieplak, P.; Cornell, W.D.; Kollman, P.A. A Well-Behaved Electrostatic Potential Based Method Using Charge Restraints for Deriving Atomic Charges: The RESP Model. J. Phys. Chem. 1993, 97, 10269-10280. [CrossRef]

73. Kühne, T.D.; Iannuzzi, M.; Del Ben, M.; Rybkin, V.V.; Seewald, P.; Stein, F.; Laino, T.; Khaliullin, R.Z.; Schütt, O.; Schiffmann, F.; et al. CP2K: An electronic structure and molecular dynamics software package-Quickstep: Efficient and accurate electronic structure calculations. J. Chem. Phys. 2020, 152, 194103. [CrossRef]

74. Jorgensen, W.L.; Chandrasekhar, J.; Madura, J.D.; Impey, R.W.; Klein, M.L. Comparison of simple potential functions for simulating liquid water. J. Chem. Phys. 1983, 79, 926-935. [CrossRef]

75. Price, D.J.; Brooks, I.C.L. A modified TIP3P water potential for simulation with Ewald summation. J. Chem. Phys. 2004, 121, 10096-10103. [CrossRef]

76. Lippert, G.; Hutter, J.; Parrinello, M. A hybrid Gaussian and plane wave density functional scheme. Mol. Phys. 1997, 92, 477-487. [CrossRef]

77. Hutter, J.; Iannuzzi, M.; Schiffmann, F.; VandeVondele, J. CP2K: Atomistic simulations of condensed matter systems. WIREs Comput. Mol. Sci. 2014, 4, 15-25. [CrossRef]

78. VandeVondele, J.; Hutter, J. Gaussian basis sets for accurate calculations on molecular systems in gas and condensed phases. J. Chem. Phys. 2007, 127, 114105. [CrossRef]

79. Krack, M. Pseudopotentials for $\mathrm{H}$ to $\mathrm{Kr}$ optimized for gradient-corrected exchange-correlation functionals. Theor. Chem. Acc. 2005, 114, 145-152. [CrossRef]

80. Hartwigsen, C.; Goedecker, S.; Hutter, J. Relativistic separable dual-space Gaussian pseudopotentials from H to Rn. Phys. Rev. B 1998, 58, 3641-3662. [CrossRef]

81. Goedecker, S.; Teter, M.; Hutter, J. Separable dual-space Gaussian pseudopotentials. Phys. Rev. B 1996, 54, 1703-1710. [CrossRef] [PubMed]

82. Maseras, F.; Morokuma, K. IMOMM: A new integrated ab initio+ molecular mechanics geometry optimization scheme of equilibrium structures and transition states. J. Comput. Chem. 1995, 16, 1170-1179. [CrossRef]

83. Lu, X.-J.; Olson, W.K. 3DNA: A software package for the analysis, rebuilding and visualization of three-dimensional nucleic acid structures. Nucleic Acids Res. 2003, 31, 5108-5121. [CrossRef]

84. Laino, T.; Mohamed, F.; Laio, A.; Parrinello, M. An Efficient Real Space Multigrid QM/MM Electrostatic Coupling. J. Chem. Theory Comput. 2005, 1, 1176-1184. [CrossRef]

85. Laino, T.; Mohamed, F.; Laio, A.; Parrinello, M. An Efficient Linear-Scaling Electrostatic Coupling for Treating Periodic Boundary Conditions in QM/MM Simulations. J. Chem. Theory Comput. 2006, 2, 1370-1378. [CrossRef] [PubMed] 
86. Parvathy, V.R.; Bhaumik, S.R.; Chary, K.V.R.; Govil, G.; Liu, K.; Howard, F.B.; Miles, H.T. NMR structure of a parallel-stranded DNA duplex at atomic resolution. Nucleic Acids Res. 2002, 30, 1500-1511. [CrossRef] [PubMed]

87. Ono, A.; Kanazawa, H.; Ito, H.; Goto, M.; Nakamura, K.; Saneyoshi, H.; Kondo, J. A Novel DNA Helical Wire Containing Hg ${ }^{\mathrm{II}}-$ Mediated T:T and T:G Pairs. Angew. Chem. Int. Ed. 2019, 58, 16835-16838. [CrossRef]

88. Szatyłowicz, H.; Sadlej-Sosnowska, N. Characterizing the Strength of Individual Hydrogen Bonds in DNA Base Pairs. J. Chem. Inf. Model. 2010, 50, 2151-2161. [CrossRef]

89. Silaghi-Dumitrescu, R.; Mihály, B.; Mihály, T.; Attia, A.A.A.; Sanz Miguel, P.J.; Lippert, B. The exocyclic amino group of adenine in $\mathrm{Pt}^{\mathrm{II}}$ and $\mathrm{Pd}^{\mathrm{II}}$ complexes: A critical comparison of the $\mathrm{X}$-ray crystallographic structural data and gas phase calculations. J. Biol. Inorg. Chem. 2017, 22, 567-579. [CrossRef] [PubMed]

Sample Availability: Samples of the compounds are not available from the authors.

Publisher's Note: MDPI stays neutral with regard to jurisdictional claims in published maps and institutional affiliations.

(C) 2020 by the authors. Licensee MDPI, Basel, Switzerland. This article is an open access article distributed under the terms and conditions of the Creative Commons Attribution (CC BY) license (http://creativecommons.org/licenses/by/4.0/). 